\title{
Interplay Between Intermolecular and Intramolecular Singlet Fission in Thin Films of a Covalently Linked Terrylenediimide Dimer
}

\author{
Michelle Chen, Adam F. Coleman, Ryan M. Young, and Michael R. Wasielewski* \\ Department of Chemistry and Institute for Sustainability and Energy at Northwestern \\ Northwestern University, Evanston IL 60208-3113
}

1. Synthesis.

S3-S10

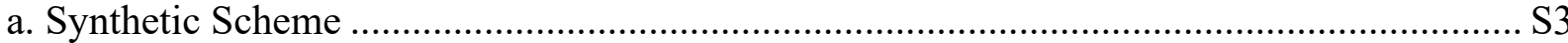

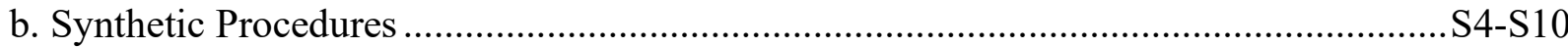

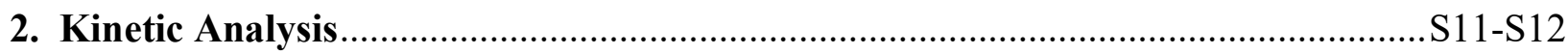

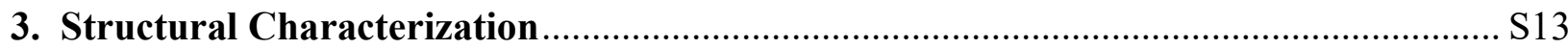

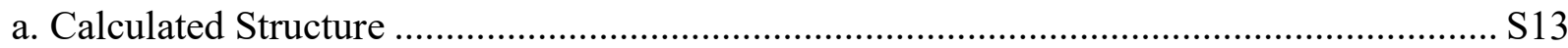

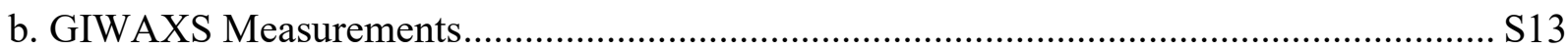

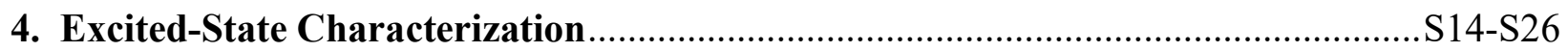

a. Triplet Sensitization of TDI-Ph-TDI........................................................................ S14

b. Global Fit of the fsTA Data of TDI-Ph-TDI in Toluene ……………………………....... S15

c. Global Fit of the nsTA Data of TDI-Ph-TDI in Toluene ............................................... S15

d. Global Fit of the fsTA Data of TDI-Ph-TDI in Benzonitrile ........................................... S16

e. Global Fit of the nsTA Data of TDI-Ph-TDI in Benzonitrile ........................................... S16

f. Time-Resolved Fluorescence of TDI-Ph-TDI in Solution ............................................... S17

g. Global Fit of the Visible fsTA Data of the TDI-Ph-TDI Unannealed Film....................... S18

h. Time-Resolved Fluorescence of the TDI-Ph-TDI Unannealed Film................................. S18

i. Global Fit of the Visible fsTA Data of the TDI-Ph-TDI Thermally Annealed Film.......... S19

j. Time-Resolved Fluorescence of the TDI-Ph-TDI Thermally Annealed Film.................... S19

k. Global Fit of the Visible fsTA Data of the TDI-Ph-TDI Chlorobenzene SVA Film ........ S20

1. Time-Resolved Fluorescence of the TDI-Ph-TDI Chlorobenzene SVA Film ( 2 ns Window)

m. Time-Resolved Fluorescence of the TDI-Ph-TDI Chlorobenzene SVA Film (100 ns

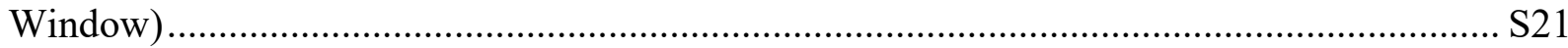

n. Global Fits of the NIR fsTA Data of the TDI-Ph-TDI Films ......................................... S22

o. Global Fit of the $1 \mathrm{kHz}$ fsTA Data of the TDI-Ph-TDI Chlorobenzene SVA Film .......... S23 
p. nsTA Data of the TDI-Ph-TDI Films............................................................................ S24

q. Full nsTA Spectra of the TDI-Ph-TDI Chlorobenzene SVA Film .................................... S25

r. Comparisons Between TDI-Ph-TDI in Solution Film.................................................. S25

s. Thermal Difference Spectra of the TDI-Ph-TDI Films ................................................. S26

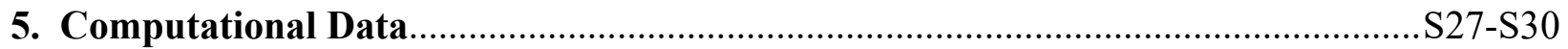

a. Full TDI-Ph-TDI Geometry (MMFF94 Force Field)...............................................S27-S29

b. Simplified TDI-Ph-TDI Geometry (B3LYP/6-31G*) …………………………….... S29-30

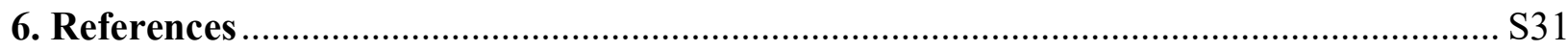




\section{Synthesis}

Spacer

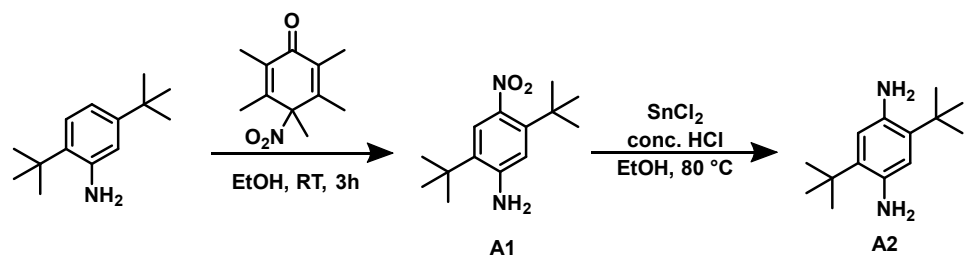
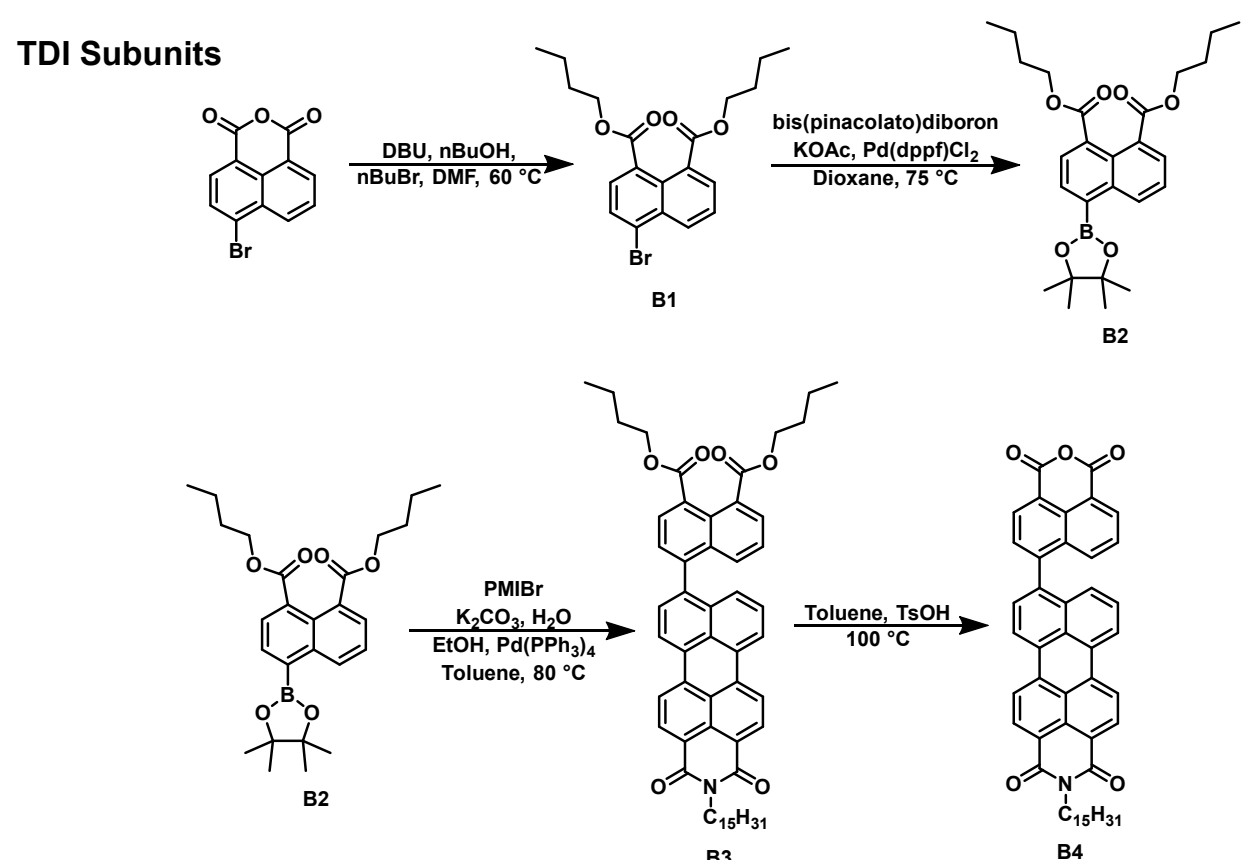

Dimer

B3

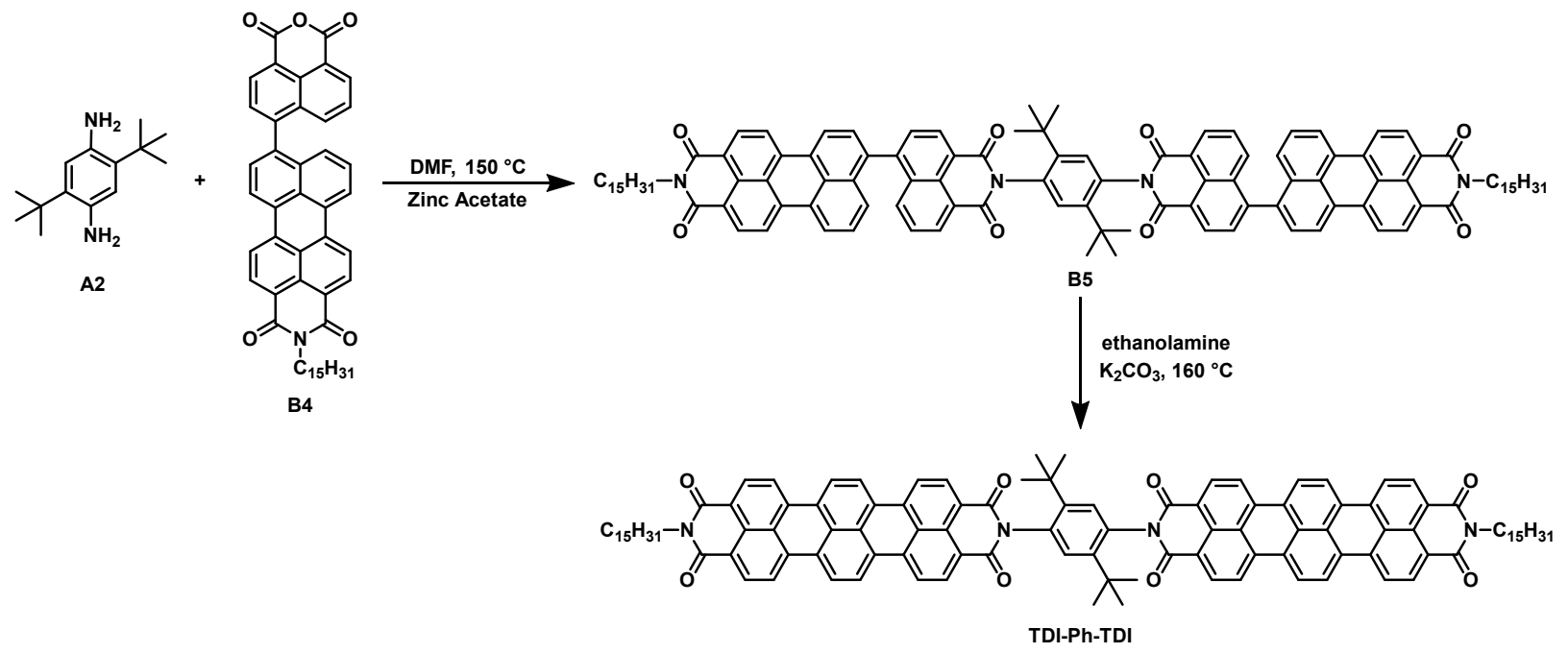

Figure S1. Synthetic scheme of TDI-Ph-TDI. 
${ }^{1} \mathrm{H}$ NMR spectra were collected at ambient temperature and at $80{ }^{\circ} \mathrm{C}$ at 500 and $400 \mathrm{MHz}$, respectively; ${ }^{13} \mathrm{C}$ NMR spectra were collected at ambient temperature at $126 \mathrm{MHz}$. Chemical shifts are reported in ppm relative to chloroform and tetrachloroethane. Mass spectrometry was performed at the Integrated Molecular Structure Education and Research Center (IMSERC) at Northwestern University on the Bruker Impact-II to generate high-resolution HR-ESI-MS and on the Agilent 6210 LC-TOF to generate high-resolution HR-APCI-MS and HR-APPI-MS. All solvent and reagents were obtained from commercial suppliers and used without further purification. Column chromatography was performed on silica gel from Macherey-Nagel. Synthesis of N-(1-heptyloctly)-9-bromo-perylene-3,4-dicarboximide (PMIBr) has been previously reported. ${ }^{1}$

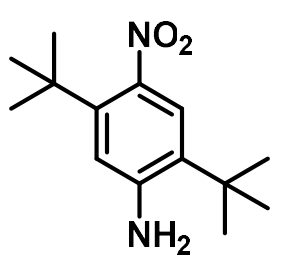

2,5-di-tert-butyl-4-nitroaniline (A1). 2,5-di-tert-butylaniline (500 mg, $2.4 \mathrm{mmol})$, 2,3,5,6tetrabromo-4-methyl-4-nitro-2,5-cyclohexadien-1-one (1.139 g, $2.4 \mathrm{mmol})$, and EtOH (12.2 mL) were combined and stirred for $3 \mathrm{~h}$ at r.t. The reaction mixture was poured into water. The resulting mixture was extracted with EtOAc, washed with water, dried over $\mathrm{Na}_{2} \mathrm{SO}_{4}$, and evaporated under reduced pressure. Column chromatography $\left(\mathrm{SiO}_{2}\right.$, hexanes $/ \mathrm{CH}_{2} \mathrm{Cl}_{2}$ 3:2) afforded the product as a yellow solid (180 mg, 30\%). ${ }^{1} \mathrm{H}$ NMR $\left(500 \mathrm{MHz}, \mathrm{CDCl}_{3}, 25{ }^{\circ} \mathrm{C}\right) \delta 7.36(\mathrm{~s}, 1 \mathrm{H}), 6.65(\mathrm{~s}, 1 \mathrm{H}), 4.16$

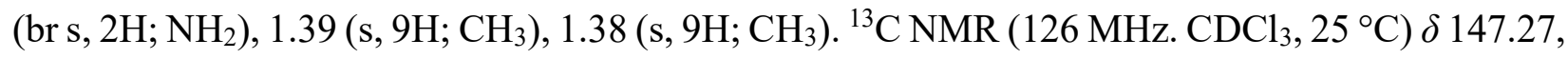
$143.11,141.98,130.88,124.73,116.21,35.25\left(C-\mathrm{CH}_{3}\right), 33.97\left(C-\mathrm{CH}_{3}\right), 30.72\left(\mathrm{CH}_{3}\right), 29.32\left(\mathrm{CH}_{3}\right)$. HR-ESI-MS: $m / z$ calcd for $\mathrm{C}_{14} \mathrm{H}_{23} \mathrm{~N}_{2} \mathrm{O}_{2}{ }^{+}\left([M+\mathrm{H}]^{+}\right)$251.1754, found: 251.1750 . 


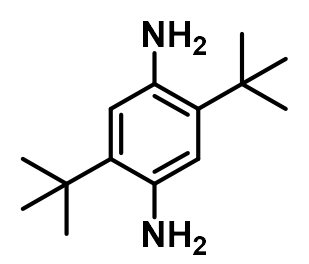

1,4-diamino-2,5-di-tert-butylbenzene (A2). 2,5-di-tert-butyl-4-nitroaniline (137 mg, 0.5 mmol), $\mathrm{SnCl}_{2}(548 \mathrm{mg})$, concentrated hydrochloric acid $(0.6 \mathrm{~mL})$, and ethanol $(12 \mathrm{~mL})$ were combined in a round bottom flask. The reaction mixture was heated at $80{ }^{\circ} \mathrm{C}$ for $3 \mathrm{~h}$. After cooling to room temperature, the reaction mixture was basified until $\mathrm{pH} 13$ with a potassium hydroxide solution. The resulting mixture was extracted with $\mathrm{CH}_{2} \mathrm{Cl}_{2}$, washed was basic water, dried over $\mathrm{Na}_{2} \mathrm{SO}_{4}$, and evaporated under reduced pressure. The solid was dissolved in $\mathrm{CH}_{2} \mathrm{Cl}_{2}$ and filtered through a celite plug. The filtrate was evaporated under reduced pressure to afford a gray-white solid (67 mg, 56\%). ${ }^{1} \mathrm{H}$ NMR $\left(500 \mathrm{MHz}, \mathrm{CDCl}_{3}, 25{ }^{\circ} \mathrm{C}\right) \delta 6.57(\mathrm{~s}, 2 \mathrm{H} ; \mathrm{CH}), 3.45\left(\mathrm{br} \mathrm{s}, 4 \mathrm{H} ; \mathrm{NH}_{2}\right), 1.38(\mathrm{~s}, 18 \mathrm{H}$; $\left.\mathrm{CH}_{3}\right) .{ }^{13} \mathrm{C}$ NMR $\left(126 \mathrm{MHz} . \mathrm{CDCl}_{3}, 25^{\circ} \mathrm{C}\right) \delta 136.55,117.55,34.01\left(\mathrm{C}-\left(\mathrm{CH}_{3}\right)_{3}\right), 29.85\left(\mathrm{CH}_{3}\right) . \mathrm{HR}-$ APCI-MS: $m / z$ calcd for $\mathrm{C}_{14} \mathrm{H}_{25} \mathrm{~N}_{2}{ }^{+}\left([M+\mathrm{H}]^{+}\right)$221.2012, found: 221.2001 .

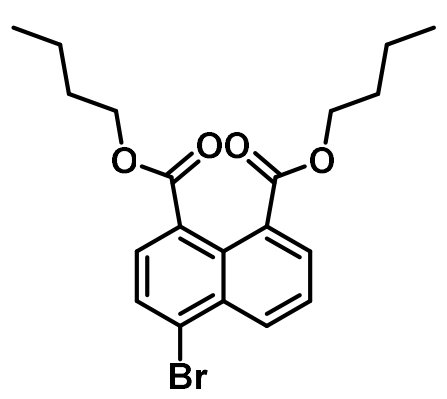

1,8-dibutoxycarbonyl-4-bromonaphthalene (B1). 4-bromo-1,8-naphthalic anhydride (1.02 g, $3.7 \mathrm{mmol}), 1,8$-diazabicyclo[5.4.0]undec-7-ene (1.11 mL, $7.4 \mathrm{mmol})$, n-butanol (2.7 mL, 30 $\mathrm{mmol})$, and DMF (25 mL) were combined and stirred at $60{ }^{\circ} \mathrm{C}$ for 30 minutes. 1-bromobutane (3.18 $\mathrm{mL}, 29 \mathrm{mmol})$ in DMF $(15 \mathrm{~mL})$ was added to the reaction mixture and heated for an 
additional $3 \mathrm{~h}$. After cooling, the reaction mixture was poured into $400 \mathrm{~mL}$ of water. The mixture was then extracted with $\mathrm{CH}_{2} \mathrm{Cl}_{2}$, washed with water, dried over $\mathrm{Na}_{2} \mathrm{SO}_{4}$, and evaporated under reduced pressure to yield a brown oil (610 $\mathrm{mg}, 41 \%)$. The compound was used without further purification. ${ }^{1} \mathrm{H} \mathrm{NMR}\left(500 \mathrm{MHz}, \mathrm{CDCl}_{3}, 25^{\circ} \mathrm{C}\right) \delta 8.48(\mathrm{dd}, J=8.6,1.3 \mathrm{~Hz}, 1 \mathrm{H}), 8.05(\mathrm{dd}, J=7.2$, $1.3 \mathrm{~Hz}, 1 \mathrm{H}), 7.89-7.80(\mathrm{~m}, 2 \mathrm{H}), 7.64(\mathrm{dd}, J=8.6,7.1 \mathrm{~Hz}, 1 \mathrm{H}), 4.30(\mathrm{td}, J=6.9,2.0 \mathrm{~Hz}, 4 \mathrm{H}$; $\mathrm{OCH}_{2}$ ), 1.74 (pd, J = 6.8, 1.6 Hz, 4H; $\mathrm{CH}_{2}$ ), 1.45 (hd, J = 7.4, $2.9 \mathrm{~Hz}, 4 \mathrm{H} ; \mathrm{CH}_{2}$ ), 0.97 (td, J = 7.4, $\left.1.1 \mathrm{~Hz}, 6 \mathrm{H} ; \mathrm{CH}_{3}\right) .{ }^{13} \mathrm{C} \mathrm{NMR}\left(126 \mathrm{MHz} . \mathrm{CDCl}_{3}, 25{ }^{\circ} \mathrm{C}\right) \delta 168.59(\mathrm{C}=\mathrm{O}), 168.42(\mathrm{C}=\mathrm{O}), 132.92$, $131.45,130.93,130.83,130.28,130.03,129.74,128.98,127.58,126.73,65.53(C-\mathrm{O}), 30.71(C-$ $\left.\mathrm{CH}_{2}\right), 19.35\left(C-\mathrm{CH}_{3}\right), 13.90\left(\mathrm{CH}_{3}\right)$. HR-APCI-MS: $m / z$ calcd for $\mathrm{C}_{20} \mathrm{H}_{23} \mathrm{BrNaO}_{4}^{+}\left([M+\mathrm{Na}]^{+}\right)$ 429.0672, found: 429.0680 .

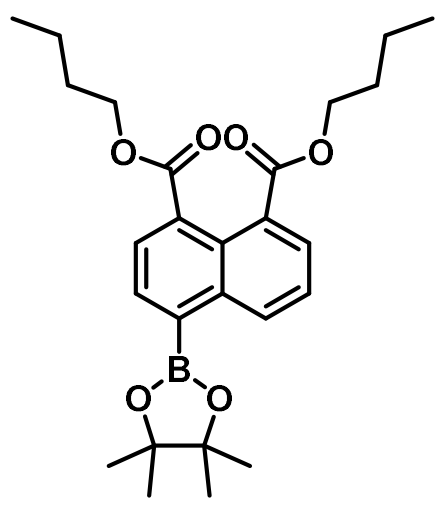

\section{1,8-dibutoxycarbonyl-4-(4,4,5,5-tetramethyl-1,3,2-dioxaborolane-2-yl)naphthalene}

(B2). 1,8-dibutoxycarbonyl-4-bromonaphthalene (503 mg, $1.2 \mathrm{mmol}$ ), bis(pinacolato)diboron (343 mg, $1.4 \mathrm{mmol})$, potassium acetate $(358 \mathrm{mg})$, and toluene $(16.1 \mathrm{~mL})$ were combined into a $50 \mathrm{~mL}$ two neck round bottom flask. The flask was purged with $\mathrm{N}_{2}$ for 15 minutes and $\operatorname{Pd}(\mathrm{dppf}) \mathrm{Cl}_{2}(53 \mathrm{mg})$ was added. The flask was purged with $\mathrm{N}_{2}$ for 15 additional minutes and the resulting reaction mixture was heated at $80^{\circ} \mathrm{C}$ overnight. The reaction mixture was cooled to room temperature and poured into $40 \mathrm{~mL}$ of $\mathrm{CH}_{2} \mathrm{Cl}_{2}$. The mixture was then extracted with $\mathrm{CH}_{2} \mathrm{Cl}_{2}$, washed with water, 
dried over $\mathrm{Na}_{2} \mathrm{SO}_{4}$, and evaporated under reduced pressure. Column chromatography $\left(\mathrm{SiO}_{2}\right.$, $\left.\mathrm{CH}_{2} \mathrm{Cl}_{2}\right)$ afforded the product as a clear oil $(290 \mathrm{mg}, 46 \%) .{ }^{1} \mathrm{H}$ NMR $\left(500 \mathrm{MHz}, \mathrm{CDCl}_{3}, 25^{\circ} \mathrm{C}\right) \delta$ $8.96(\mathrm{dd}, J=8.5,1.4 \mathrm{~Hz}, 1 \mathrm{H}), 8.11(\mathrm{~d}, J=7.1 \mathrm{~Hz}, 1 \mathrm{H}), 8.00(\mathrm{dd}, J=7.2,1.4 \mathrm{~Hz}, 1 \mathrm{H}), 7.95(\mathrm{~d}, J=$ $7.1 \mathrm{~Hz}, 1 \mathrm{H}), 7.57(\mathrm{dd}, J=8.5,7.1 \mathrm{~Hz}, 1 \mathrm{H}), 4.29\left(\mathrm{td}, J=6.9,1.5 \mathrm{~Hz}, 4 \mathrm{H} ; \mathrm{OCH}_{2}\right), 1.81-1.66(\mathrm{~m}$, 4H; $\left.\mathrm{CH}_{2}\right), 1.49-1.39$ (m, 4H; $\left.\mathrm{CH}_{2}\right), 1.43\left(\mathrm{~s}, 12 \mathrm{H} ; \mathrm{CH}_{3}\right), 0.96$ (td, $\left.J=7.4,2.7 \mathrm{~Hz}, 6 \mathrm{H} ; \mathrm{CH}_{3}\right) .{ }^{13} \mathrm{C}$ $\operatorname{NMR}\left(126 \mathrm{MHz} . \mathrm{CDCl}_{3}, 25^{\circ} \mathrm{C}\right) \delta 169.22(\mathrm{C}=\mathrm{O}), 169.11(\mathrm{C}=\mathrm{O}), 137.91,134.89,132.99,132.73$, 130.32, 129.68, 128.71, 127.37, 125.54, $\left.84.37\left(C-\mathrm{CH}_{3}\right)_{2}\right), 65.30(C-\mathrm{O}), 65.20(C-\mathrm{O}), 30.75(C-$ $\left.\mathrm{CH}_{2}\right), 30.72\left(C-\mathrm{CH}_{2}\right), 25.06\left(\mathrm{CH}_{3}\right), 19.37\left(C-\mathrm{CH}_{3}\right), 19.34\left(C-\mathrm{CH}_{3}\right), 13.90\left(\mathrm{CH}_{3}\right)$. HR-APCI-MS: $m / z$ calcd for $\mathrm{C}_{26} \mathrm{H}_{35} \mathrm{BNaO}_{6}{ }^{+}\left([M+\mathrm{Na}]^{+}\right) 477.2419$, found: 477.2419 .

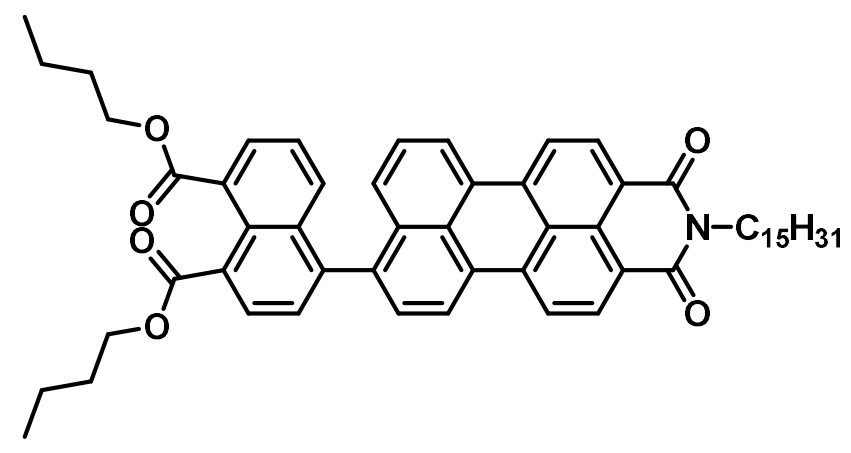

Compound B3. 1,8-dibutoxycarbonyl-4-(4,4,5,5-tetramethyl-1,3,2-dioxaborolane-2yl)naphthalene (290 mg, $0.6 \mathrm{mmol}$ ), PMIBr (465 mg, $0.8 \mathrm{mmol}$ ), potassium carbonate (358 mg), water $(2.9 \mathrm{~mL})$, ethanol $(2.9 \mathrm{~mL})$, and toluene $(28.6 \mathrm{~mL})$ were combined in a $100 \mathrm{~mL}$ two neck round bottom flask. The flask was purged with $\mathrm{N}_{2}$ for 15 minutes and $\mathrm{Pd}\left(\mathrm{PPh}_{3}\right)_{4}(29 \mathrm{mg})$ was added. The flask was purged with $\mathrm{N}_{2}$ for 15 more minutes and the resulting reaction mixture was heated at $80{ }^{\circ} \mathrm{C}$ overnight. After cooling to room temperature, the reaction mixture was extracted with $\mathrm{CH}_{2} \mathrm{Cl}_{2}$ and washed with water. The organic layers were combined, dried over $\mathrm{Na}_{2} \mathrm{SO}_{4}$, and evaporated under reduced pressure to afford a red gel. Column chromatography $\left(\mathrm{SiO}_{2}, \mathrm{CH}_{2} \mathrm{Cl}_{2}\right)$ 
afforded the product as a red solid $(416 \mathrm{mg}, 76 \%) .{ }^{1} \mathrm{H}$ NMR $\left(500 \mathrm{MHz}, \mathrm{CDCl}_{3}, 25^{\circ} \mathrm{C}\right) \delta 8.70-8.56$ (m, 2H), $8.53(\mathrm{~d}, J=7.8 \mathrm{~Hz}, 1 \mathrm{H}), 8.51-8.38(\mathrm{~m}, 3 \mathrm{H}), 8.15(\mathrm{~d}, J=7.1 \mathrm{~Hz}, 1 \mathrm{H}), 8.02(\mathrm{~d}, J=6.9$ $\mathrm{Hz}, 1 \mathrm{H}), 7.68-7.57(\mathrm{~m}, 3 \mathrm{H}), 7.44(\mathrm{t}, J=8.0 \mathrm{~Hz}, 1 \mathrm{H}), 7.42-7.34(\mathrm{~m}, 2 \mathrm{H}), 5.26-5.17(\mathrm{~m}, 1 \mathrm{H} ; \mathrm{NCH})$, 4.49-4.32 (m, 4H; $\left.\mathrm{OCH}_{2}\right), 2.36-2.20(\mathrm{~m}, 2 \mathrm{H}), 1.96-1.76(\mathrm{~m}, 6 \mathrm{H}), 1.65-1.45(\mathrm{~m}, 6 \mathrm{H}), 1.43-1.17$ (m, 18H), 1.08-0.97 (m, 6H), $0.83\left(\mathrm{t}, J=6.6 \mathrm{~Hz}, 6 \mathrm{H} ; \mathrm{CH}_{3}\right) .{ }^{13} \mathrm{C} \mathrm{NMR}\left(126 \mathrm{MHz} . \mathrm{CDCl}_{3}, 25{ }^{\circ} \mathrm{C}\right)$ $\delta 169.13(\mathrm{C}=\mathrm{O}), 168.99(\mathrm{C}=\mathrm{O}), 141.86,140.37,133.83,133.76,130.80,130.67,130.57,130.22$, $130.09,129.71,129.52,129.32,129.13,128.27,127.91,127.47,126.73,125.80,123.89,123.12$ 120.63, 120.49, $65.57(C-\mathrm{O}), 65.53(C-\mathrm{O}), 54.60(\mathrm{~N}-\mathrm{CH}), 32.57,31.96,30.83,30.81,29.70,29.38$ 27.16, 22.76, 19.44, 19.42, $14.20\left(\mathrm{CH}_{3}\right), 13.96\left(\mathrm{CH}_{3}\right)$. HR-APCI-MS: $\mathrm{m} / z$ calcd for $\mathrm{C}_{57} \mathrm{H}_{64} \mathrm{NO}_{6}{ }^{+}$ $\left([M+\mathrm{H}]^{+}\right) 858.4728$, found: 858.4715 .

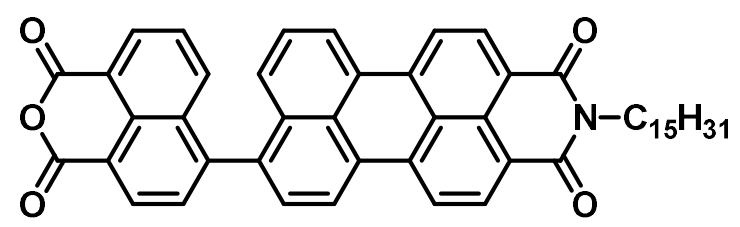

Compound B4. B3 (508 mg, $0.6 \mathrm{mmol}$ ), p-toluenesulfonic acid (572 mg, $3.3 \mathrm{mmol}$ ), and toluene $(54 \mathrm{~mL})$ were combined in a $250 \mathrm{~mL}$ round bottom flask. The reaction mixture was heated at 100 ${ }^{\circ} \mathrm{C}$ overnight. After cooling to room temperature, the reaction mixture was extracted with $\mathrm{CH}_{2} \mathrm{Cl}_{2}$ and washed with water. The organic layers were combined, dried over $\mathrm{Na}_{2} \mathrm{SO}_{4}$, and evaporated under reduced pressure to afford the product as a red solid (400 mg, 93\%). The compound was used without further purification. ${ }^{1} \mathrm{H}$ NMR $\left(500 \mathrm{MHz}, \mathrm{CDCl}_{3}, 25^{\circ} \mathrm{C}\right) \delta 8.80(\mathrm{~d}, J=7.4 \mathrm{~Hz}, 1 \mathrm{H})$, $8.73-8.58(\mathrm{~m}, 4 \mathrm{H}), 8.55(\mathrm{~d}, J=8.1 \mathrm{~Hz}, 1 \mathrm{H}), 8.51(\mathrm{dd}, J=7.8,2.6 \mathrm{~Hz}, 2 \mathrm{H}), 7.98(\mathrm{dd}, J=8.5,1.2$ $\mathrm{Hz}, 1 \mathrm{H}), 7.91(\mathrm{~d}, J=7.4 \mathrm{~Hz}, 1 \mathrm{H}), 7.69$ (dd, $J=8.5,7.2 \mathrm{~Hz}, 1 \mathrm{H}), 7.65$ (d, $J=7.8 \mathrm{~Hz}, 1 \mathrm{H}), 7.51$ (t, $J=7.9 \mathrm{~Hz}, 1 \mathrm{H}), 7.35(\mathrm{~d}, J=8.4 \mathrm{~Hz}, 1 \mathrm{H}), 5.25-5.17(\mathrm{~m}, 1 \mathrm{H}), 2.32-2.21(\mathrm{~m}, 2 \mathrm{H}), 1.92-1.81(\mathrm{~m}$, 2H), $1.40-1.16(\mathrm{~m}, 20 \mathrm{H}), 0.83\left(\mathrm{t}, J=7.2 \mathrm{~Hz}, 6 \mathrm{H} ; \mathrm{CH}_{3}\right) .{ }^{13} \mathrm{C} \mathrm{NMR}\left(126 \mathrm{MHz} . \mathrm{CDCl}_{3}, 25{ }^{\circ} \mathrm{C}\right) \delta$ 
$160.67(\mathrm{C}=\mathrm{O}), 160.52(\mathrm{C}=\mathrm{O}), 146.27,138.10,134.19,133.86,133.35,133.14,132.41,132.32$, $131.55,130.81,130.65,130.08,129.58,129.14,128.87,128.77,128.48,128.44,127.93,127.92$, $126.79,124.06,122.96,120.99,120.88,119.37,118.96,77.41,77.16,76.91,54.69(\mathrm{~N}-\mathrm{CH}), 32.56$, 31.96, 29.86, 29.70, 29.39, 27.16, 22.77, 14.22. HR-APCI-MS: $m / z$ calcd for $\mathrm{C}_{49} \mathrm{H}_{46} \mathrm{NO}_{5}{ }^{+}\left([M+\mathrm{H}]^{+}\right)$ 728.3371, found: 728.3362 .

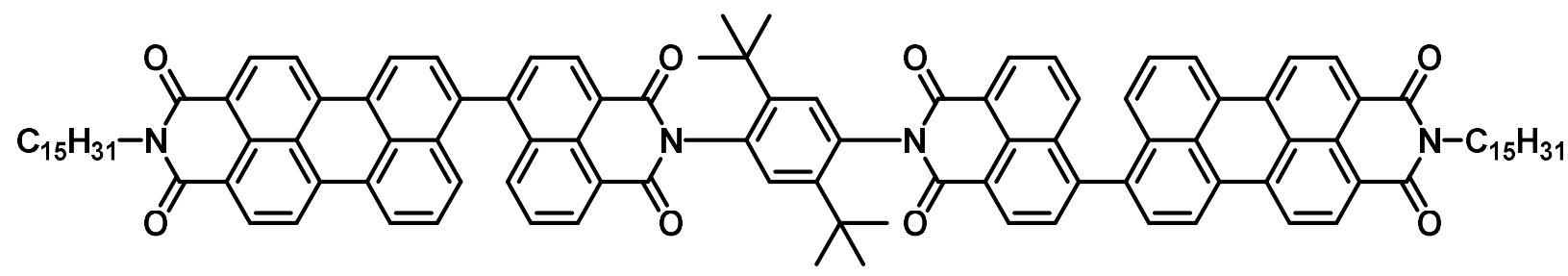

Compound B5. B4, (337 mg, $0.5 \mathrm{mmol})$, 1,4-diamino-2,5-di-tert-butylbenzene (32.7 mg, 0.1 mmol), zinc acetate $(9 \mathrm{mg})$, and DMF $(1.1 \mathrm{~mL})$ were combined in a $25 \mathrm{~mL}$ two neck round bottom flask. The reaction mixture was purged with $\mathrm{N}_{2}$ for 15 minutes and subsequently heated at $150{ }^{\circ} \mathrm{C}$ for 5 days. After cooling to room temperature, the reaction mixture was evaporated under reduced pressure. Column chromatography $\left(\mathrm{SiO}_{2}, \mathrm{CHCl}_{3} /\right.$ hexanes, 4:1) afforded the product as a red solid (78 mg, 26\%). ${ }^{1} \mathrm{H}$ NMR $\left(500 \mathrm{MHz}, \mathrm{CDCl}_{3}, 25^{\circ} \mathrm{C}\right) \delta 8.87(\mathrm{~d}, J=7.2 \mathrm{~Hz}, 2 \mathrm{H}), 8.76(\mathrm{~d}, J=7.1 \mathrm{~Hz}$, 2H), $8.71-8.59(\mathrm{~m}, 6 \mathrm{H}), 8.57-8.46(\mathrm{~m}, 6 \mathrm{H}), 7.99-7.94(\mathrm{~m}, 2 \mathrm{H}), 7.92(\mathrm{~d}, J=7.3 \mathrm{~Hz}, 2 \mathrm{H}), 7.76-$ $7.66(\mathrm{~m}, 4 \mathrm{H}), 7.59-7.49(\mathrm{~m}, 3 \mathrm{H}), 7.44(\mathrm{~d}, J=8.4 \mathrm{~Hz}, 1 \mathrm{H}), 7.35(\mathrm{~d}, J=2.4 \mathrm{~Hz}, 1 \mathrm{H}), 7.33(\mathrm{~d}, J=$ $2.5 \mathrm{~Hz}, 1 \mathrm{H}), 5.26-5.17(\mathrm{~m}, 2 \mathrm{H} ; \mathrm{NCH}), 2.34-2.22(\mathrm{~m}, 4 \mathrm{H}), 1.94-1.82(\mathrm{~m}, 4 \mathrm{H}), 1.40-1.16(\mathrm{~m}$, $40 \mathrm{H}), 0.83\left(\mathrm{t}, \mathrm{J}=6.7 \mathrm{~Hz}, 12 \mathrm{H} ; \mathrm{CH}_{3}\right) .{ }^{13} \mathrm{C} \mathrm{NMR}\left(126 \mathrm{MHz} \mathrm{CDCl}_{3}, 25{ }^{\circ} \mathrm{C}\right) \delta 165.15(\mathrm{C}=\mathrm{O}), 164.98$ $(\mathrm{C}=\mathrm{O}), 146.59,146.55,144.95,144.87,139.06,133.98,133.93,133.60,133.57,133.07,132.22$, $132.15,131.51,131.45,130.31,130.12,129.96,129.36,129.24,129.18,129.12,129.09,128.47$ $127.78,127.55,126.81,124.02,123.50,123.20,123.16,123.07,120.87,120.76,54.66(\mathrm{~N}-\mathrm{CH})$, 
35.69, 32.58, 31.97, 31.77, 31.71, 29.71, 29.39, 27.16, 22.77, $14.22\left(\mathrm{CH}_{3}\right)$. HR-ESI-MS: $\mathrm{m} / z$ calcd for $\mathrm{C}_{122} \mathrm{H}_{114} \mathrm{~N}_{5} \mathrm{O}_{8}{ }^{+}\left(\left[M+\mathrm{NH}_{4}\right]^{+}\right)$1657.8695, found: 1657.8679 .

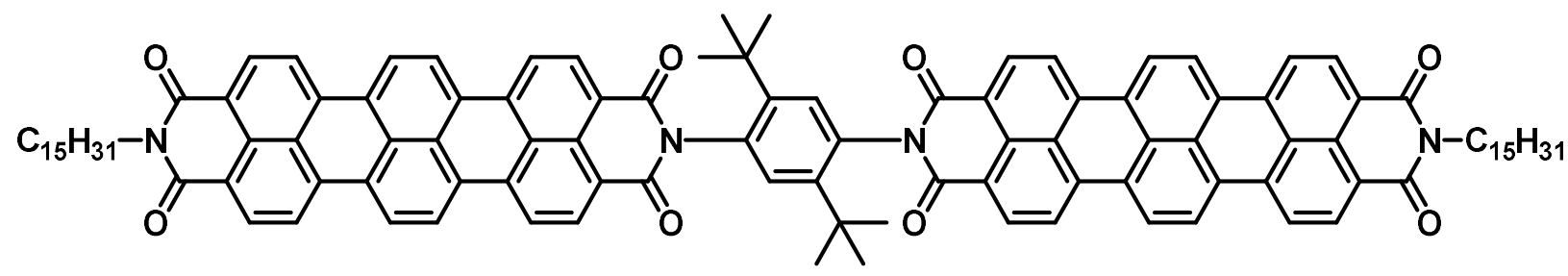

TDI-Ph-TDI. B5 (78 mg, $0.05 \mathrm{mmol})$, potassium carbonate $(661 \mathrm{mg})$, and ethanolamine $(0.91 \mathrm{~g})$ were combined in a $25 \mathrm{~mL}$ two neck round bottom flask. The reaction mixture was purged with $\mathrm{N}_{2}$ for 15 minutes and subsequently heated at $160^{\circ} \mathrm{C}$ for $3 \mathrm{~h}$. The reaction mixture was poured into water after being cooled to room temperature. The suspension was filtered and washed with water. The solid was dissolved in $\mathrm{CH}_{2} \mathrm{Cl}_{2}$ and filtered through a celite plug. The resulting filtrate was evaporated under reduced pressure. Column chromatography $\left(\mathrm{SiO}_{2}, \mathrm{CHCl}_{3}\right)$ afforded a blue solid (42 mg, 54\%). ${ }^{1} \mathrm{H}$ NMR (400 MHz, $\left.\mathrm{CD}_{2} \mathrm{Cl}_{4}, 80{ }^{\circ} \mathrm{C}\right) \delta 8.85-8.79(\mathrm{~m}, 4 \mathrm{H}), 8.78-8.65(\mathrm{~m}, 16 \mathrm{H})$, 8.65-8.59 (m, 4H), 7.35 (s, 2H; CH), 5.28-5.18 (m, 2H; NCH), 2.36-2.23 (m, 4H), 2.02-1.89 (m, $4 \mathrm{H}), 1.36-1.27(\mathrm{~m}, 40 \mathrm{H}), 0.93-0.87(\mathrm{~m}, 12 \mathrm{H}) .{ }^{13} \mathrm{C}$ NMR was not obtained. HR-APPI-MS: $m / z$ calcd for $\mathrm{C}_{122} \mathrm{H}_{106} \mathrm{~N}_{4} \mathrm{O}_{8}{ }^{+}\left([M+\mathrm{H}]^{+}\right)$1636.8084, found: 1635.8094 . 


\section{Kinetic Analysis}

The TDI-Ph-TDI in toluene fsTA data were fit to the following model:

$$
\begin{aligned}
& \frac{d[A]}{d t}=-k_{A \rightarrow B}[A] \\
& \frac{d[B]}{d t}=k_{A \rightarrow B}[A]-k_{B \rightarrow C}[B] \\
& \frac{d[C]}{d t}=k_{B \rightarrow C}[B]-k_{C \rightarrow D}[C] \\
& \frac{d[D]}{d t}=k_{C \rightarrow D}[C]
\end{aligned}
$$

where $k_{\mathrm{A} \rightarrow \mathrm{B}}$ and $k_{\mathrm{B} \rightarrow \mathrm{C}}$ are singlet relaxation rate constants and $k_{\mathrm{C} \rightarrow \mathrm{D}}$ is in the intramolecular SF rate constant. Species A and B are unrelaxed singlet excited state populations, species C is the relaxed singlet-excited state, and species $\mathrm{D}$ is the $\left(\mathrm{T}_{1} \mathrm{~T}_{1}\right)$ state formed via intramolecular $\mathrm{SF}$.

The TDI-Ph-TDI in toluene nsTA data were fit to the following model:

$$
\begin{aligned}
& \frac{d\left[A^{\prime}\right]}{d t}=-k_{A^{\prime} \rightarrow B^{\prime}}\left[A^{\prime}\right] \\
& \frac{d\left[B^{\prime}\right]}{d t}=k_{A^{\prime} \rightarrow B^{\prime}}\left[A^{\prime}\right]-k_{B^{\prime} \rightarrow G S}\left[B^{\prime}\right]
\end{aligned}
$$

where $k_{\mathrm{A}^{\prime} \rightarrow \mathrm{B}^{\prime}}$ is the intramolecular SF rate constant and $k_{\mathrm{B}^{\prime} \rightarrow \mathrm{GS}}$ is the triplet decay rate constant.

The TDI-Ph-TDI in benzonitrile fsTA data were fit to the following model:

$$
\begin{aligned}
& \frac{d[A]}{d t}=-k_{A \rightarrow B}[A] \\
& \frac{d[B]}{d t}=k_{A \rightarrow B}[A]-k_{B \rightarrow C}[B] \\
& \frac{d[C]}{d t}=k_{B \rightarrow C}[B]-k_{C \rightarrow G S}[C]
\end{aligned}
$$

where $k_{\mathrm{A} \rightarrow \mathrm{B}}$ is the singlet relaxation rate constant, $k_{\mathrm{B} \rightarrow \mathrm{C}}$ is the symmetry-breaking charge separation rate constant, and $k_{\mathrm{C} \rightarrow \mathrm{GS}}$ is the radical-pair intersystem crossing rate constant. Species 
$\mathrm{A}, \mathrm{B}$, and $\mathrm{C}$ are the unrelaxed singlet excited state, the relaxed singlet excited state, and the charge separated state, respectively.

The TDI-Ph-TDI in benzonitrile nsTA data were fit to the following model:

$$
\begin{aligned}
& \frac{d\left[A^{\prime}\right]}{d t}=-k_{A^{\prime} \rightarrow B^{\prime}}\left[A^{\prime}\right] \\
& \frac{d\left[B^{\prime}\right]}{d t}=k_{A^{\prime} \rightarrow B^{\prime}}\left[A^{\prime}\right]-k_{B^{\prime} \rightarrow C^{\prime}}\left[B^{\prime}\right] \\
& \frac{d\left[C^{\prime}\right]}{d t}=k_{B^{\prime} \rightarrow C^{\prime}}\left[B^{\prime}\right]-k_{C^{\prime} \rightarrow G S}\left[C^{\prime}\right]
\end{aligned}
$$

where $k_{\mathrm{A}^{\prime} \rightarrow \mathrm{B}^{\prime}}$ is the symmetry-breaking charge separation rate constant, $k_{\mathrm{B}^{\prime} \rightarrow \mathrm{C}^{\prime}}$ is the radical-pair intersystem crossing rate constant, and $k_{\mathrm{C}^{\prime} \rightarrow \mathrm{GS}}$ is the triplet decay rate constant. Species $\mathrm{A}^{\prime}, \mathrm{B}^{\prime}$, and $\mathrm{C}^{\prime}$ are the singlet excited state, the charge separated state, and the triplet state formed via radicalpair intersystem crossing, respectively. 


\section{Structural Characterization}

\section{Calculated Structure}

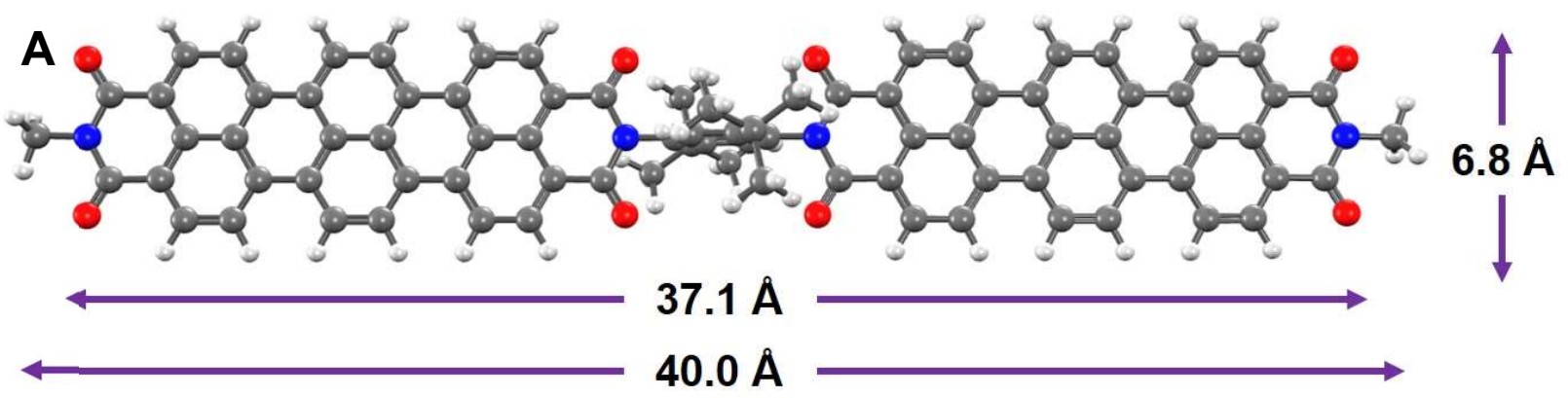

B

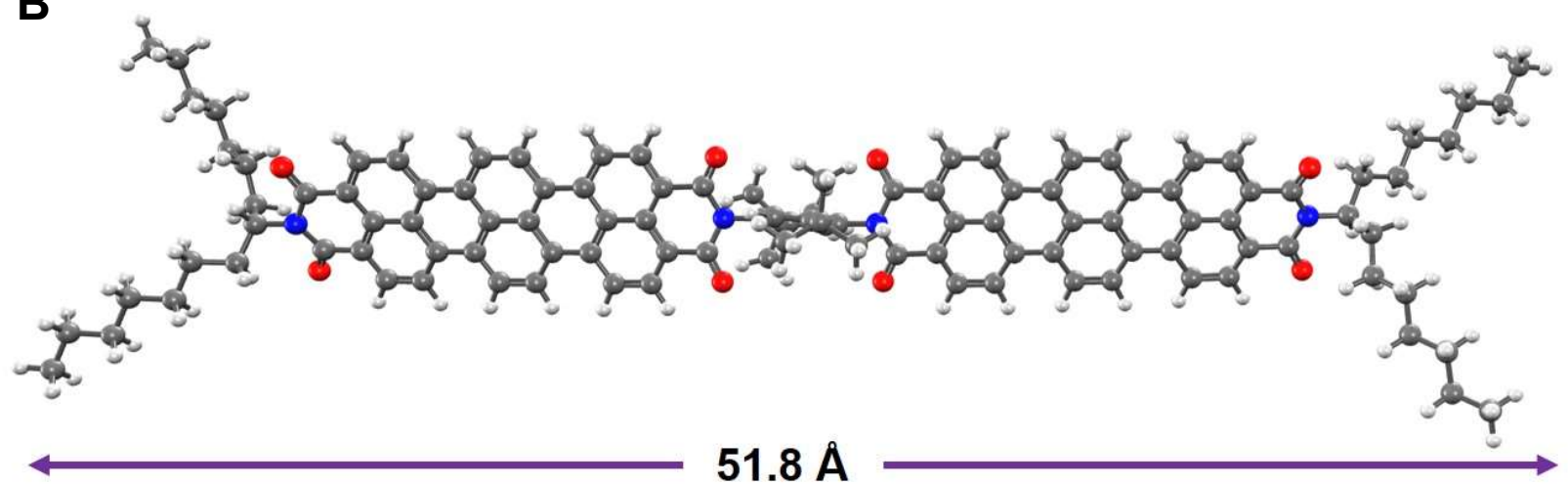

Figure S2. (A) Ground state structure of a simplified TDI-Ph-TDI calculated in QChem (B3LYP/6-31G*). (B) Full TDI-Ph-TDI structure calculated in Avogadro (MMFF94).

\section{GIWAXS Measurements}
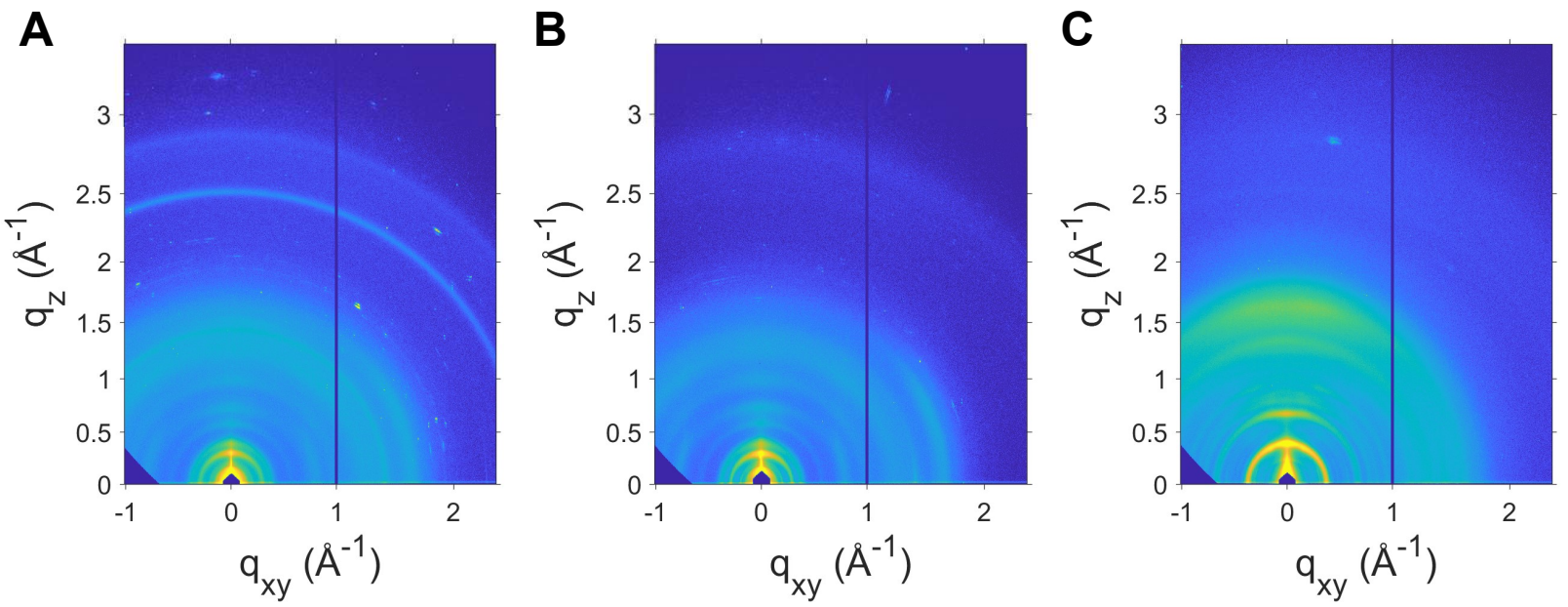

Figure S3. GIWAXS spectra of the (A) unannealed, (B) thermally annealed, and (C) chlorobenzene solvent-vapor annealed (SVA) films. 


\section{Excited-State Characterization}

\section{Triplet Sensitization of TDI-Ph-TDI}

Triplet sensitization of TDI-Ph-TDI was performed in toluene by photoexcitation of anthracene, in large excess, at $355 \mathrm{~nm}$. The anthracene $\mathrm{T}_{1}$ state $(1.85 \mathrm{eV})$ is populated by rapid intersystem crossing. The anthracene $\mathrm{T}_{1}$ state triplet energy transfers to the lower energy TDI-Ph-TDI $\mathrm{T}_{1}$ state, allowing for optical characterization of the TDI $\mathrm{T}_{1}$ state by nsTA. The sample was deoxygenated by three freeze-pump-thaw cycles.

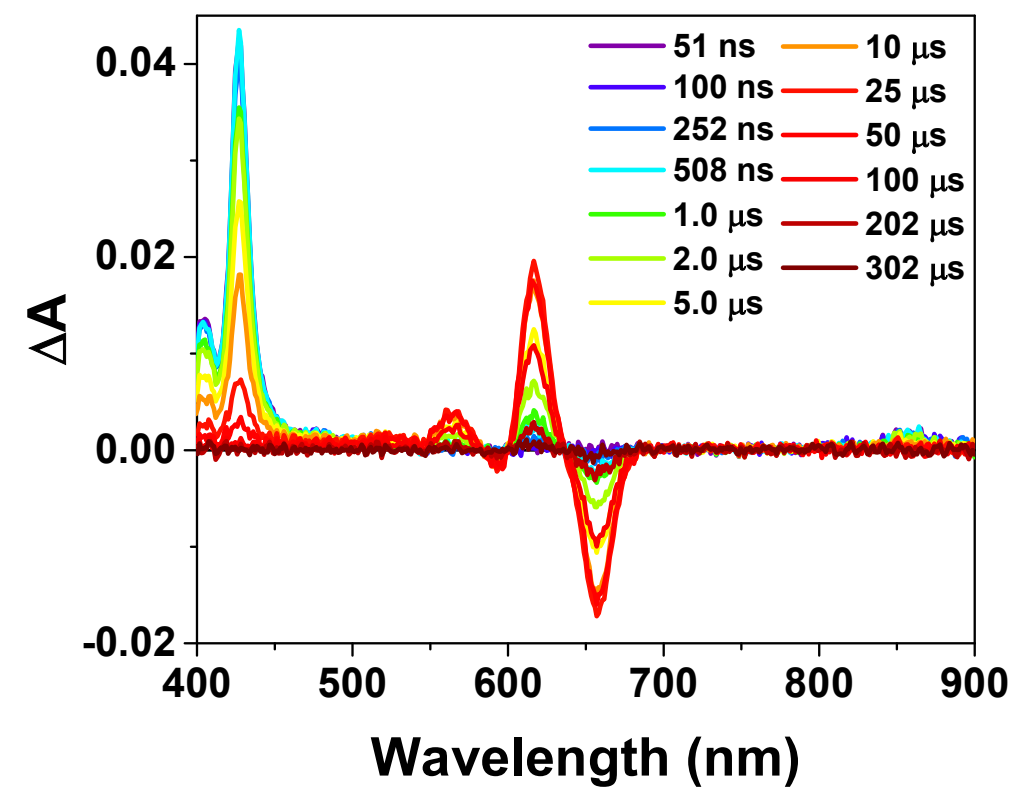

Figure S4. NsTA spectra of anthracene-sensitized TDI-Ph-TDI (orange to red, $\Delta \mathrm{t}>5 \mathrm{~ns}$ ) in toluene, $\lambda_{\mathrm{ex}}=355 \mathrm{~nm}$. 


\section{Global Fit of the fsTA Data of TDI-Ph-TDI in Toluene}
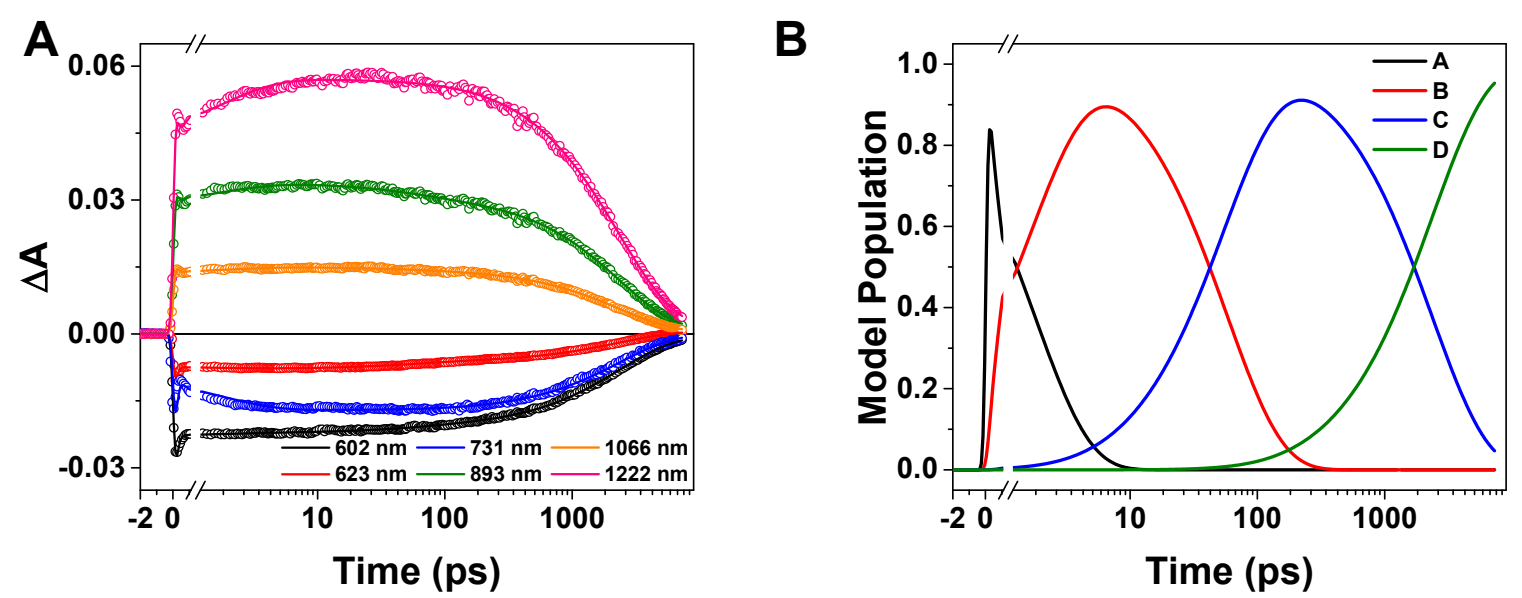

Figure S5. (A) Single-wavelength kinetics at 602 (black), 623 (red), 731 (blue), 893 (green), 1066 (orange), and $1222 \mathrm{~nm}$ (pink) and (B) population dynamics obtained by global analysis with an $\mathrm{A} \rightarrow \mathrm{B} \rightarrow \mathrm{C} \rightarrow \mathrm{D}$ model of TDI-Ph-TDI in toluene, $\lambda_{\mathrm{ex}}=655 \mathrm{~nm}$.

\section{Global Fit of the nsTA Data of TDI-Ph-TDI in Toluene}
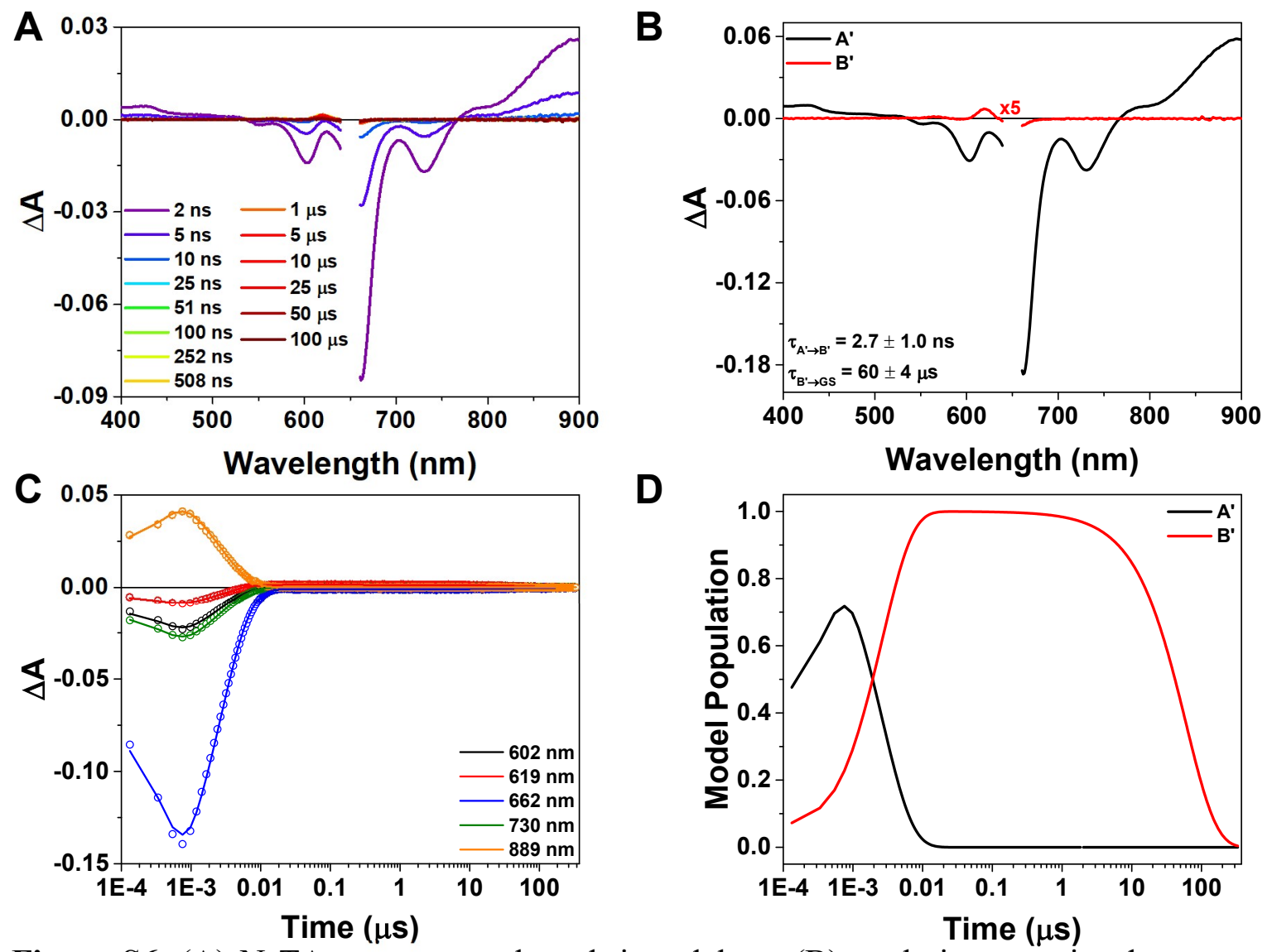

D

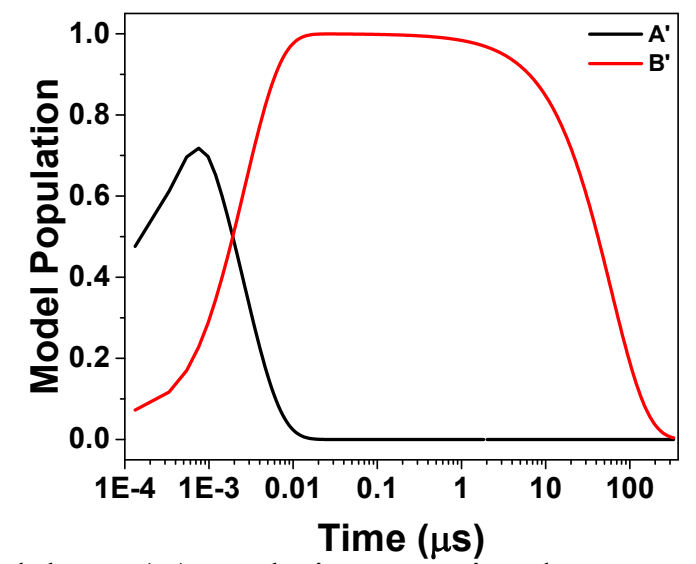

Figure S6. (A) NsTA spectra at selected time delays, (B) evolution-associated spectra, (C) single-wavelength kinetics at 602 (black), 619 (red), 662 (blue), 730 (green), and $889 \mathrm{~nm}$ (orange), and (D) population dynamics obtained by global analysis with an $\mathrm{A}^{\prime} \rightarrow \mathrm{B}^{\prime} \rightarrow$ ground model of TDI-Ph-TDI in toluene, $\lambda_{\mathrm{ex}}=655 \mathrm{~nm}$. 


\section{Global Fit of the fsTA Data of TDI-Ph-TDI in Benzonitrile}
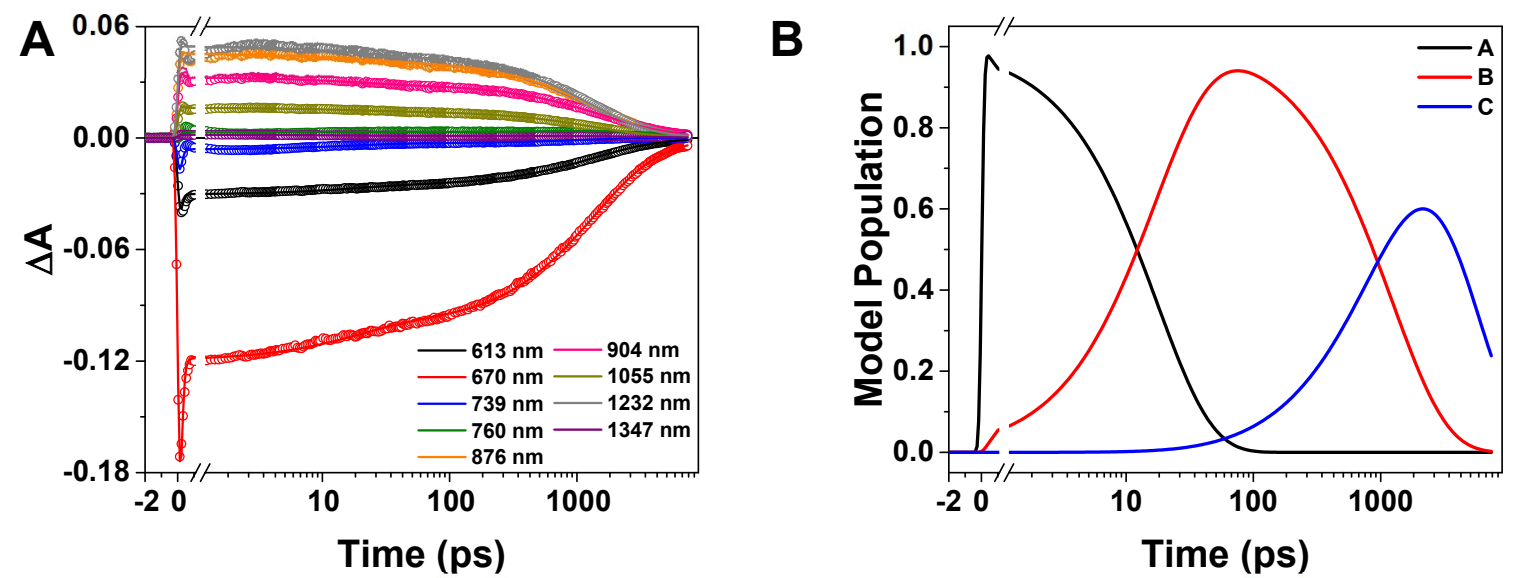

Figure S7. (A) Single-wavelength kinetics at 613 (black), 670 (red), 739 (blue), 760 (green), 876 (orange), 904 (pink), 1055 (dark yellow), 1232 (gray), and $1347 \mathrm{~nm}$ (purple) and (B) population dynamics obtained by global analysis with an $\mathrm{A} \rightarrow \mathrm{B} \rightarrow \mathrm{C} \rightarrow$ ground model of TDI-Ph-TDI in benzonitrile, $\lambda_{\mathrm{ex}}=655 \mathrm{~nm}$.

\section{Global Fit of the nsTA Data of TDI-Ph-TDI in Benzonitrile}
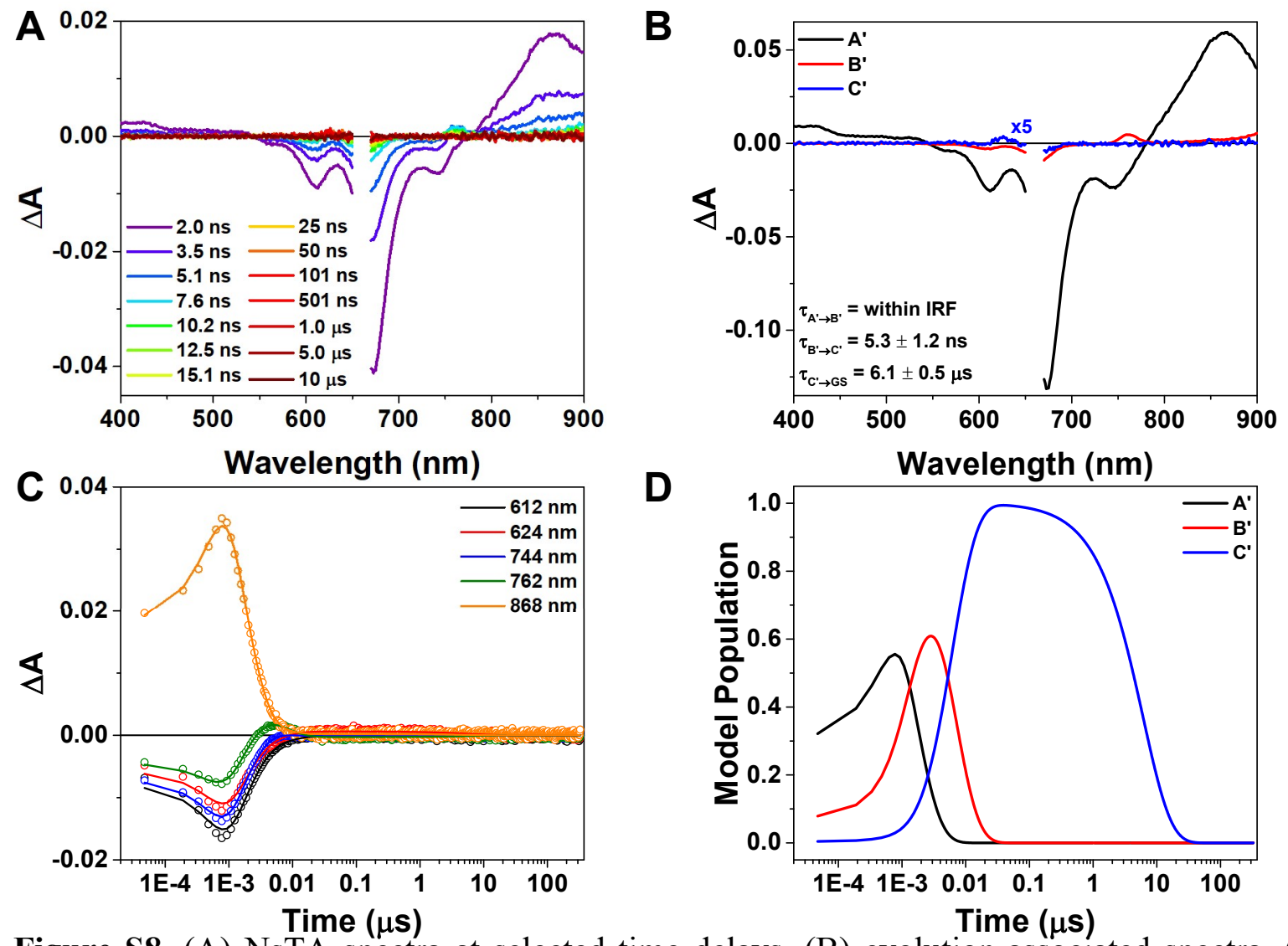

Figure S8. (A) NsTA spectra at selected time delays, (B) evolution-associated spectra, (C) single-wavelength kinetics at 612 (black), 624 (red), 744 (blue), 762 (green), and $868 \mathrm{~nm}$ (orange), and (D) population dynamics obtained by global analysis with an $\mathrm{A}^{\prime} \rightarrow \mathrm{B}^{\prime} \rightarrow \mathrm{C}^{\prime} \rightarrow$ ground model of TDI-Ph-TDI in benzonitrile, $\lambda_{\mathrm{ex}}=655 \mathrm{~nm}$. 


\section{Time-Resolved Fluorescence of TDI-Ph-TDI in Solution}

A

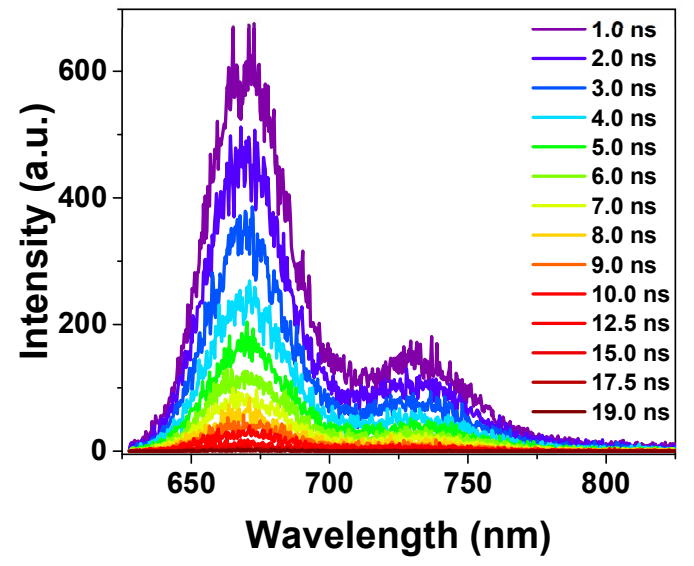

B

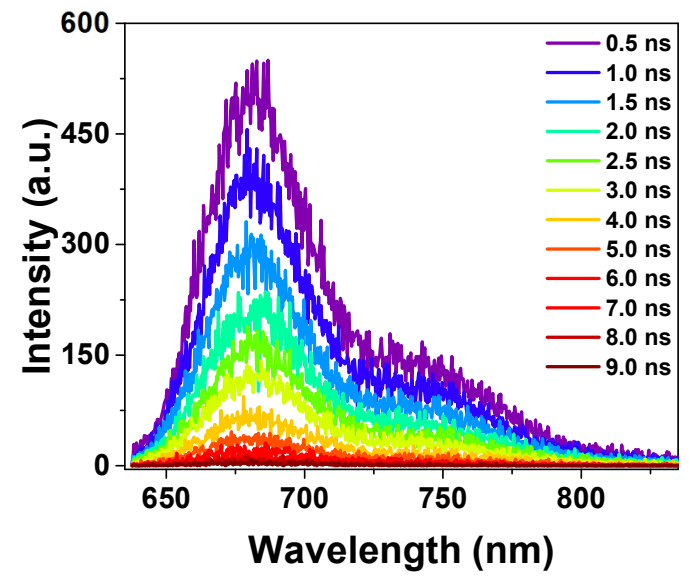

C

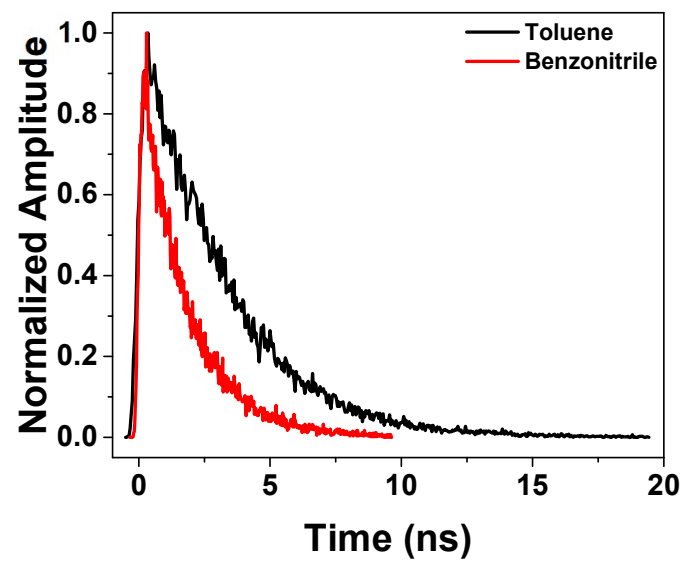

Figure S9. Time-resolved fluorescence spectra at selected time delays of TDI-Ph-TDI in (A) toluene and (B) benzonitrile, $\lambda_{\mathrm{ex}}=600 \mathrm{~nm}$. (C) Comparison of the single-wavelength kinetics at $670 \mathrm{~nm}$. 


\section{Global Fit of the Visible fsTA Data of the TDI-Ph-TDI Unannealed Film}

A

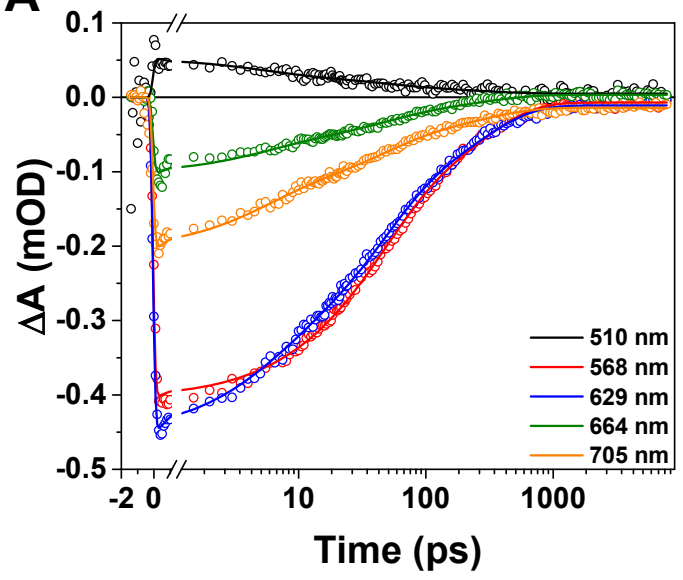

B

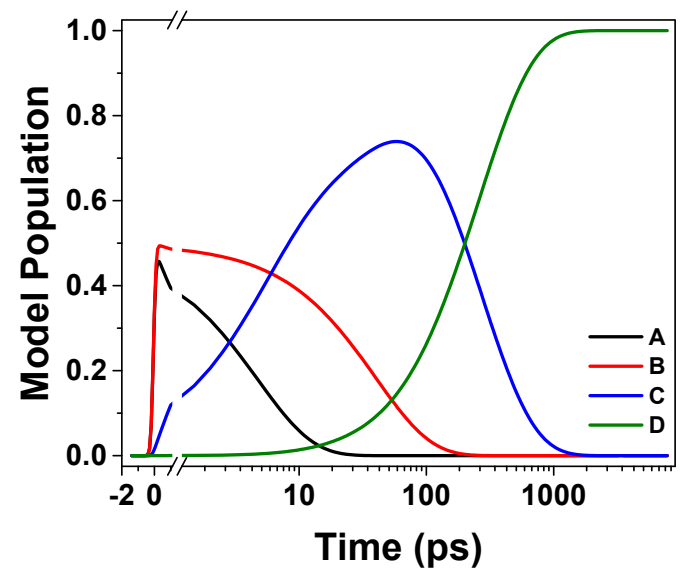

Figure S10. (A) Single-wavelength kinetics at 510 (black), 568 (red), 629 (blue), 664 (green), and $705 \mathrm{~nm}$ (orange) and (B) population dynamics obtained by global analysis with the kinetic model described in eq. 1 of the TDI-Ph-TDI unannealed film, $\lambda_{\text {ex }}=680 \mathrm{~nm}$.

\section{Time-Resolved Fluorescence of the TDI-Ph-TDI Unannealed Film}

A

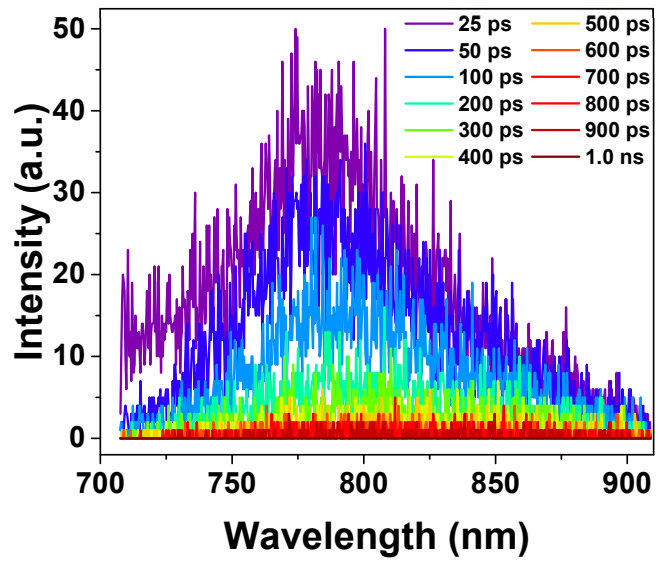

B

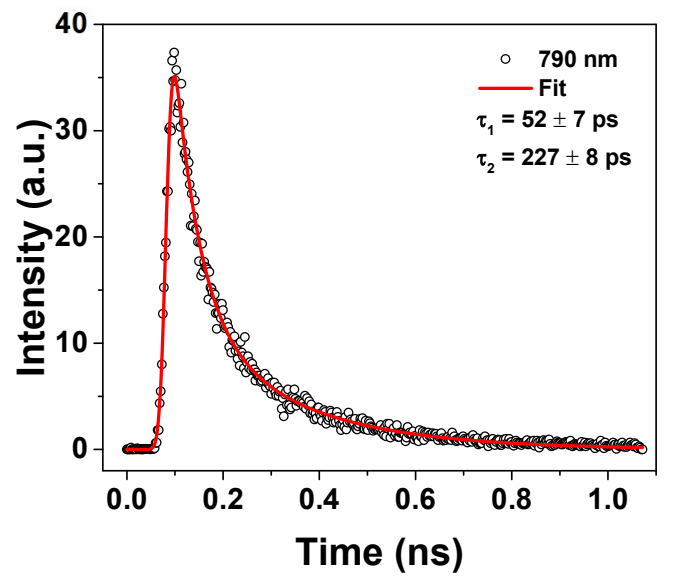

Figure S11. (A) Time-resolved fluorescence spectra at selected time delays and (B) singlewavelength kinetic fit at $790 \mathrm{~nm}$ of the TDI-Ph-TDI unannealed film collected with a $1 \mathrm{~ns}$ window, $\lambda_{\mathrm{ex}}=600 \mathrm{~nm}$. 


\section{Global Fit of the Visible fsTA Data of the TDI-Ph-TDI Thermally Annealed Film}

A

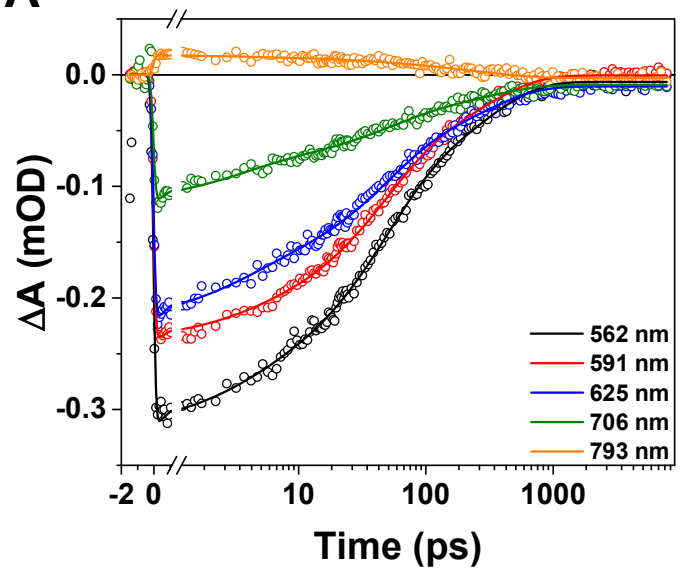

B

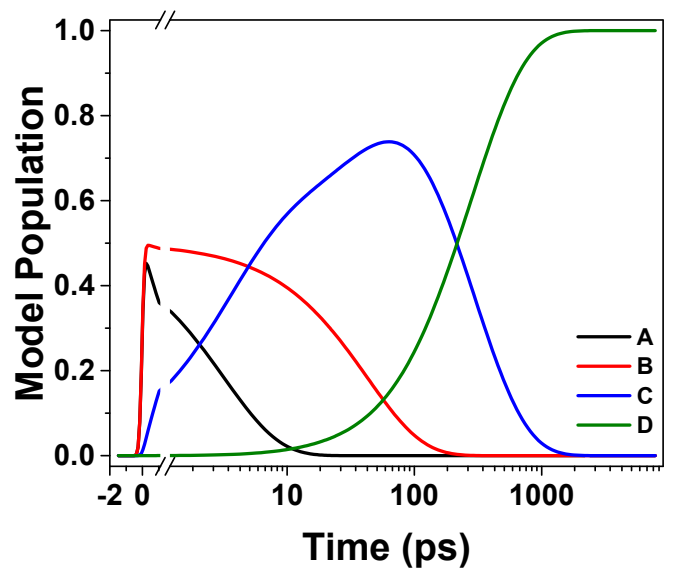

Figure S12. (A) Single-wavelength kinetics at 562 (black), 591 (red), 625 (blue), 706 (green), and $793 \mathrm{~nm}$ (orange) and (B) population dynamics obtained by global analysis with the kinetic model described in eq. 1 of the TDI-Ph-TDI thermally annealed film, $\lambda_{\mathrm{ex}}=680 \mathrm{~nm}$.

\section{Time-Resolved Fluorescence of the TDI-Ph-TDI Thermally Annealed Film}

A

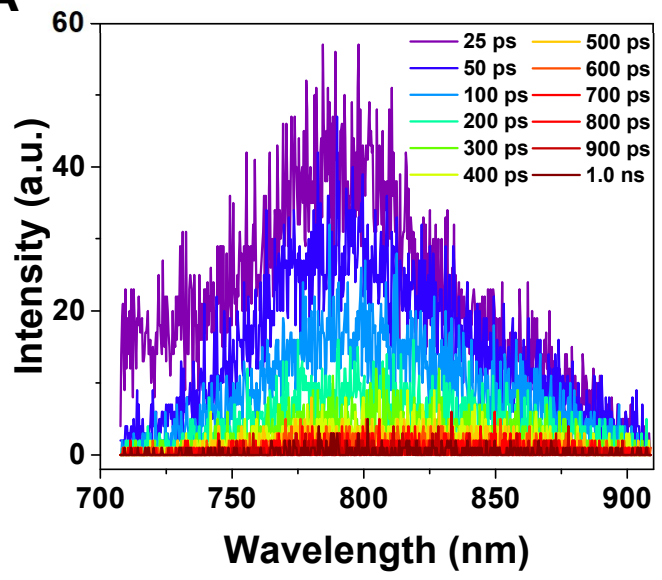

B

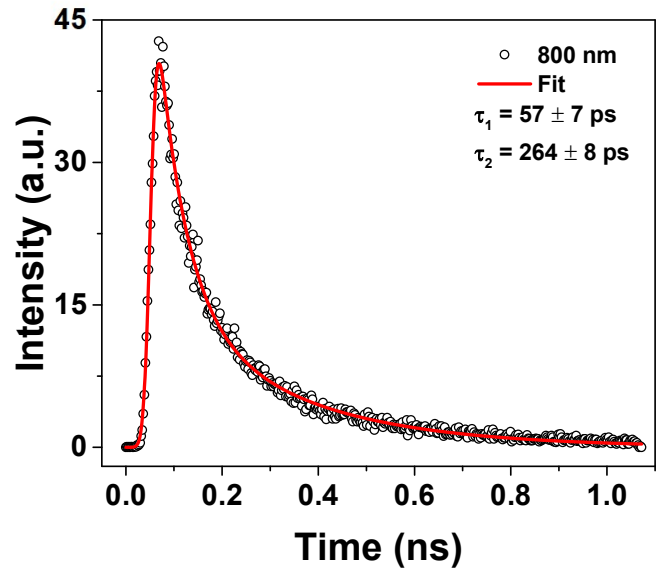

Figure S13. (A) Time-resolved fluorescence spectra at selected time delays and (B) singlewavelength kinetic fit at $800 \mathrm{~nm}$ of the TDI-Ph-TDI thermally annealed film collected with a $1 \mathrm{~ns}$ window, $\lambda_{\mathrm{ex}}=600 \mathrm{~nm}$. 


\section{Global Fit of the Visible fsTA Data of the TDI-Ph-TDI Chlorobenzene SVA Film}

A

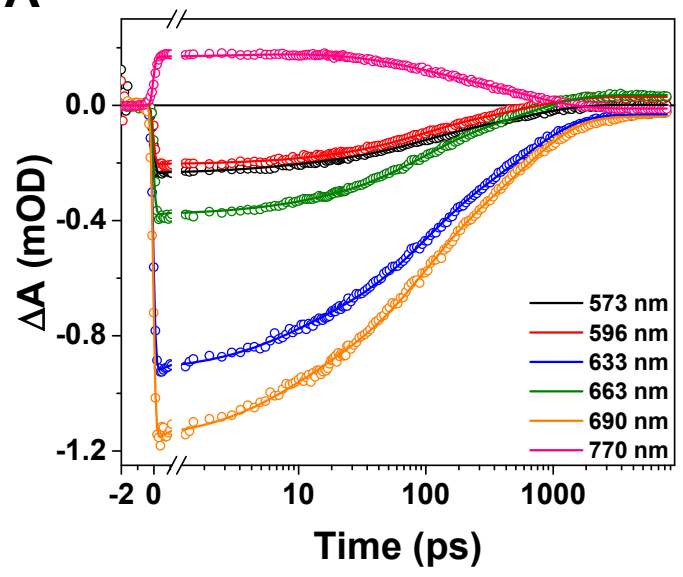

B

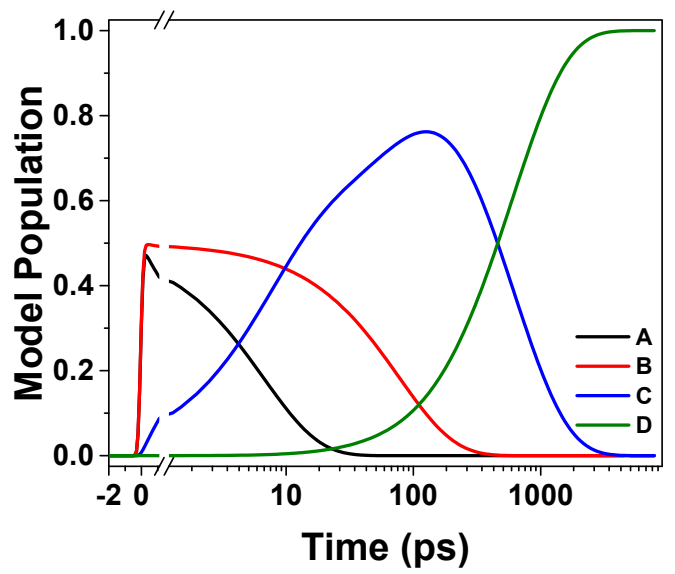

Figure S14. (A) Single-wavelength kinetics at 573 (black), 596 (red), 633 (blue), 663 (green), 690 (orange), and $770 \mathrm{~nm}$ (pink) and (B) population dynamics obtained by global analysis with the kinetic model described in eq. 1 of the TDI-Ph-TDI chlorobenzene solvent-vapor annealed film, $\lambda_{\mathrm{ex}}=680 \mathrm{~nm}$.

\section{Time-Resolved Fluorescence of the TDI-Ph-TDI Chlorobenzene SVA Film (2 ns Window)}

A

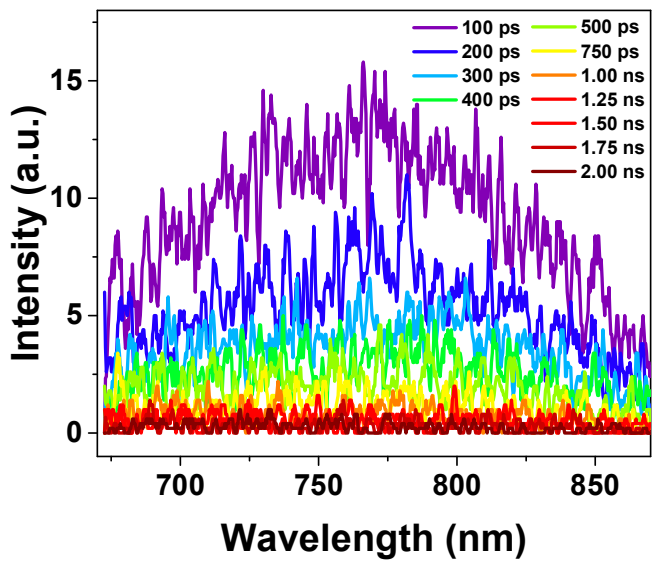

B

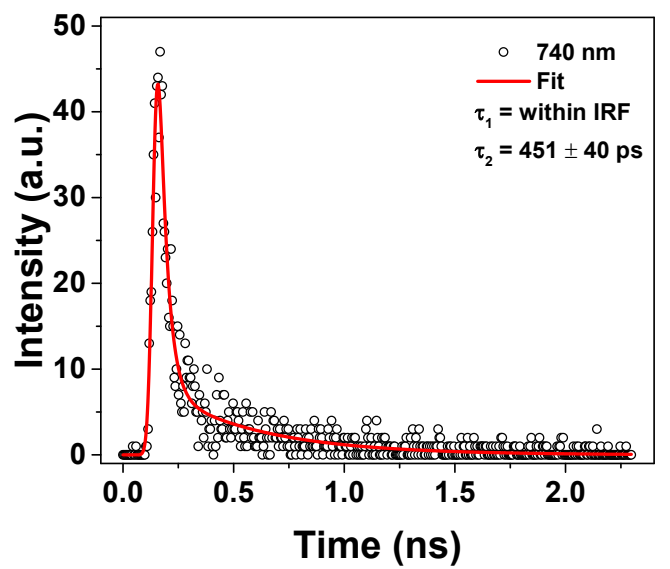

Figure S15. (A) Time-resolved fluorescence spectra at selected time delays and (B) singlewavelength kinetic fit at $740 \mathrm{~nm}$ of the TDI-Ph-TDI chlorobenzene solvent-vapor annealed film collected with a $2 \mathrm{~ns}$ window, $\lambda_{\mathrm{ex}}=600 \mathrm{~nm}$. Spectra were smoothed with 5-point adjacent averaging. 
Time-Resolved Fluorescence of the TDI-Ph-TDI Chlorobenzene SVA Film (100 ns Window)

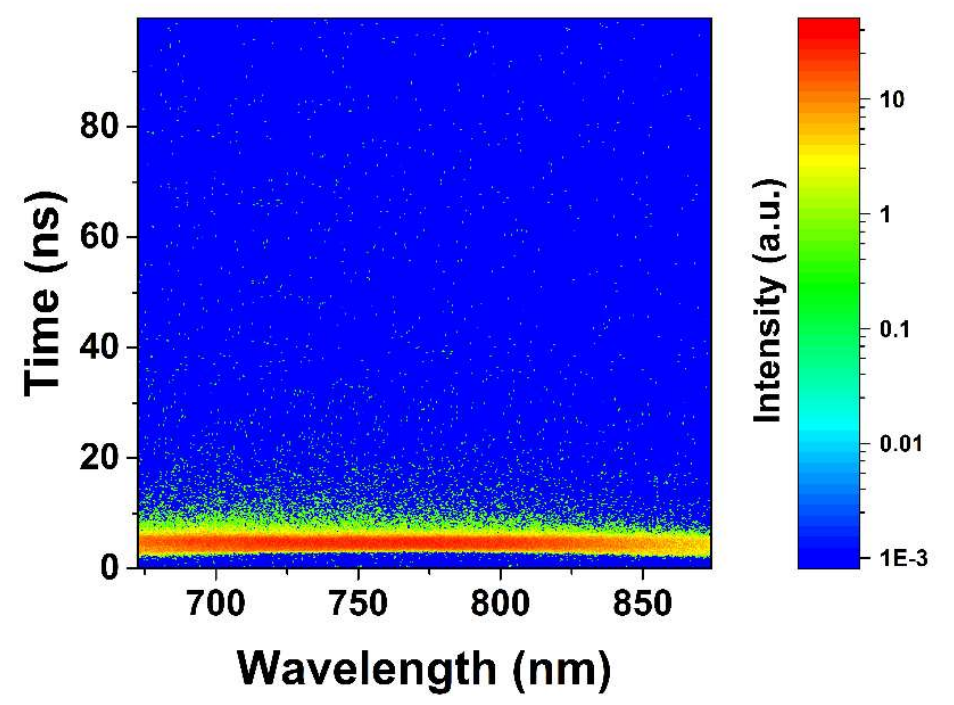

Figure S16. Contour plot of the TRF data of the TDI-PhTDI chlorobenzene solvent-vapor annealed film collected with a $100 \mathrm{~ns}$ window, $\lambda_{\mathrm{ex}}=600 \mathrm{~nm}$. 


\section{Global Fits of the NIR fsTA Data of the TDI-Ph-TDI Films}
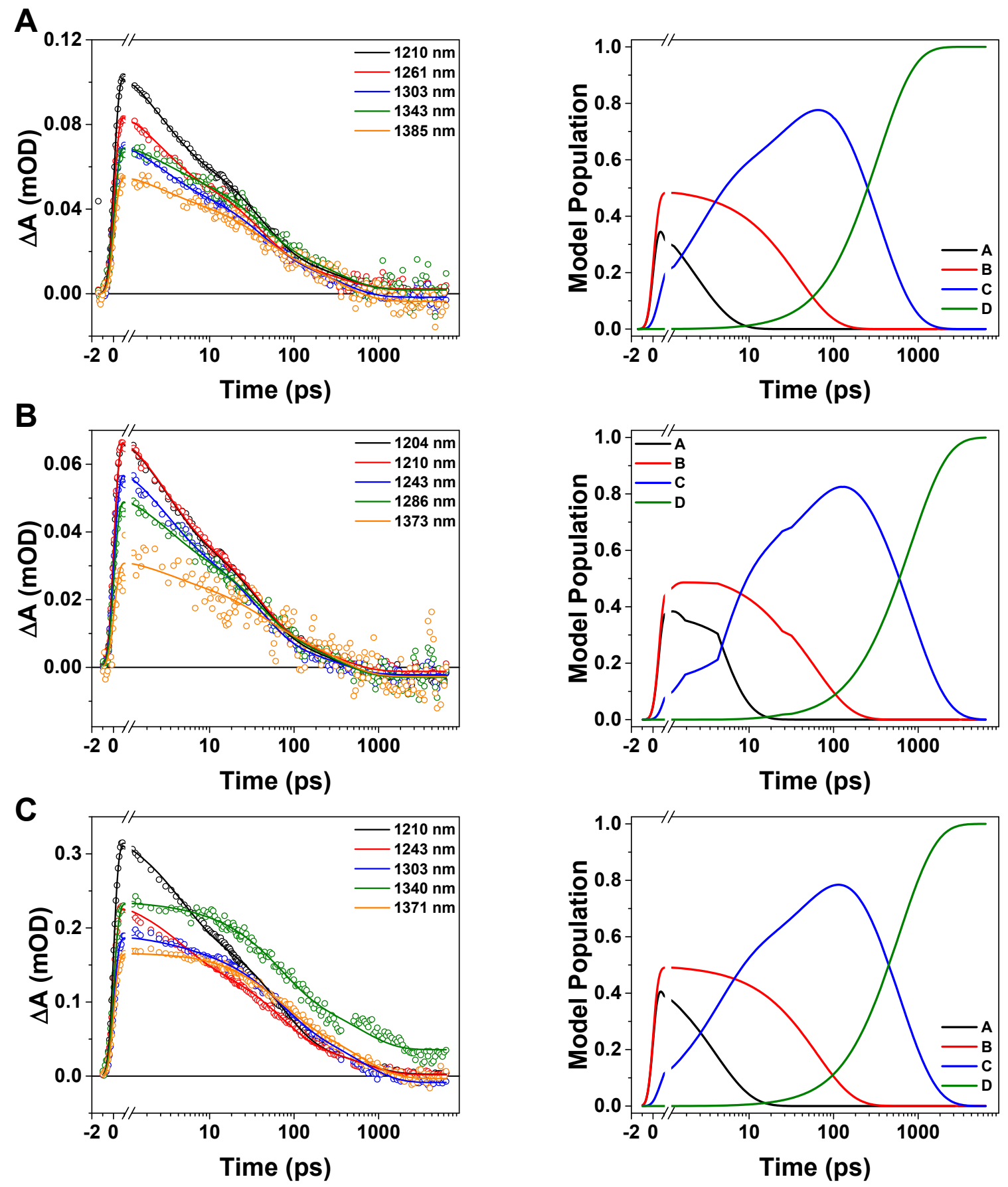

Figure S17. Single-wavelength kinetics and population dynamics obtained by global analysis with the kinetic model described in eq. 1 of the TDI-Ph-TDI (A) unannealed, (B) thermally annealed, and (C) chlorobenzene solvent-vapor annealed films, $\lambda_{\mathrm{ex}}=680 \mathrm{~nm}$. 


\section{Global Fit of the $1 \mathrm{kHz}$ fsTA Data of the TDI-Ph-TDI Chlorobenzene SVA Film}

A

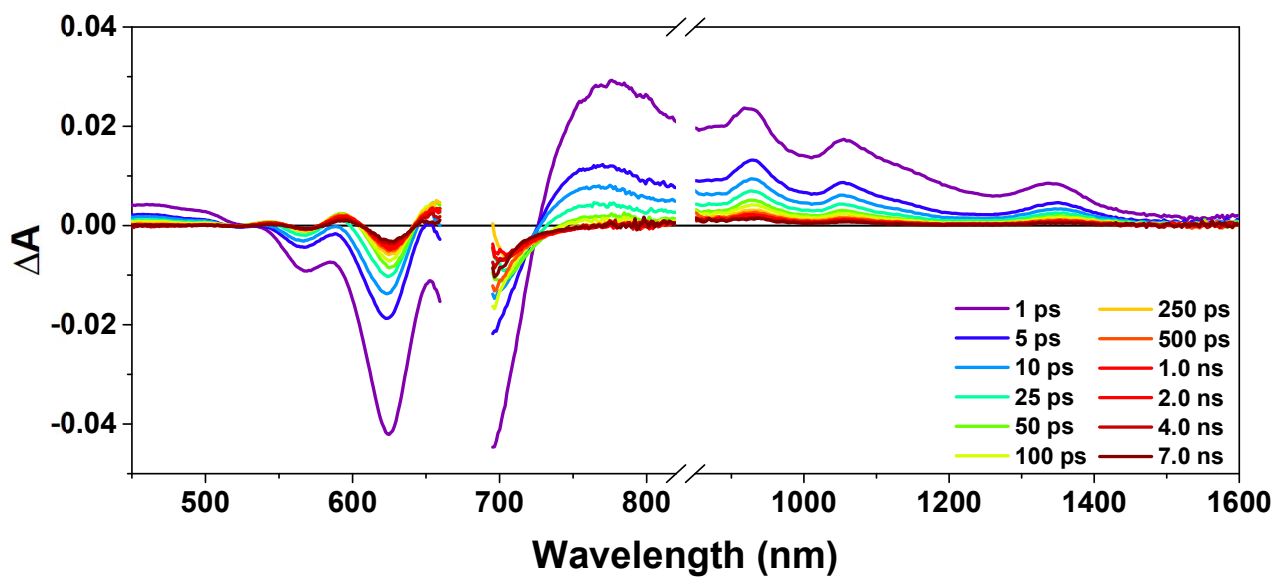

B
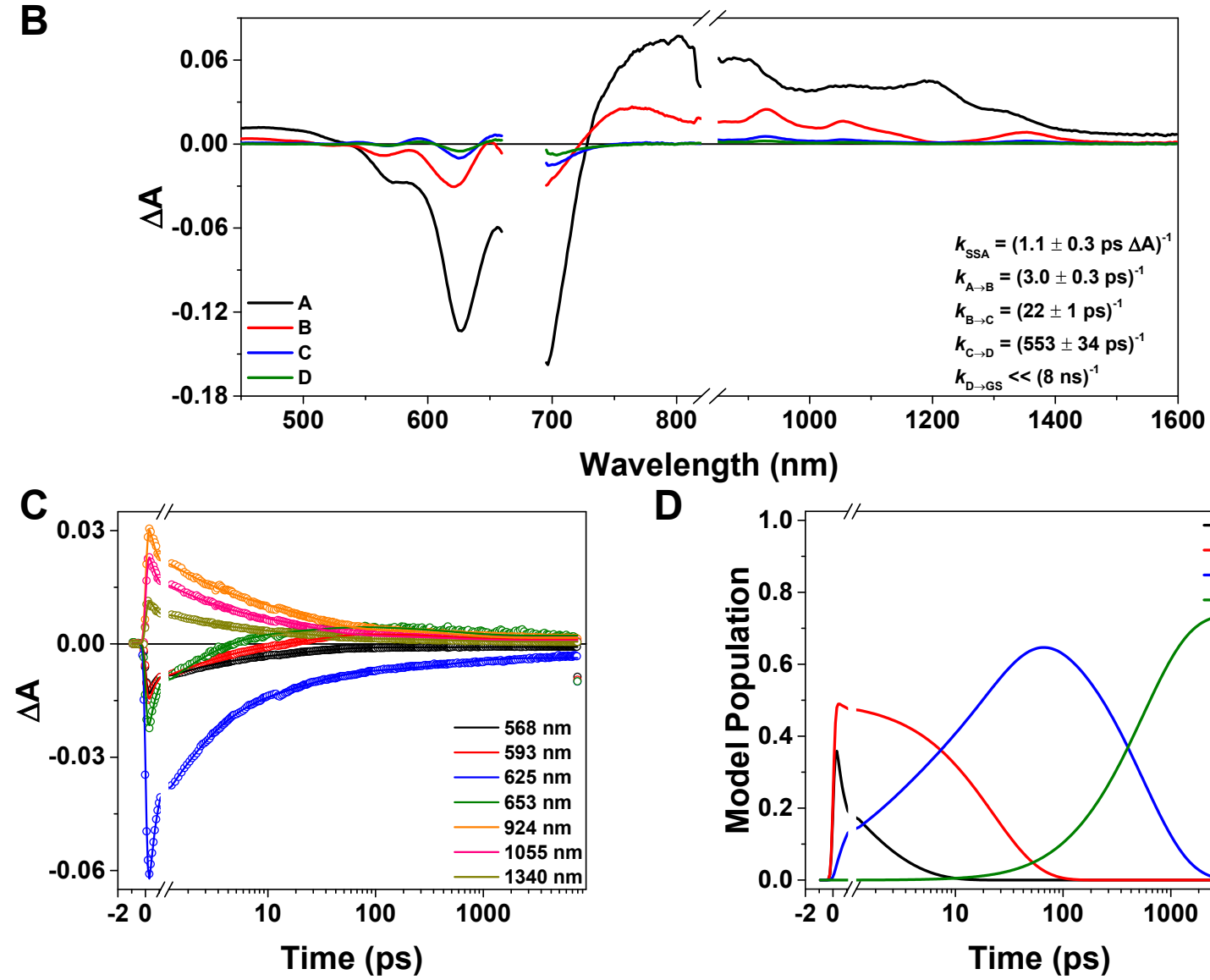

D

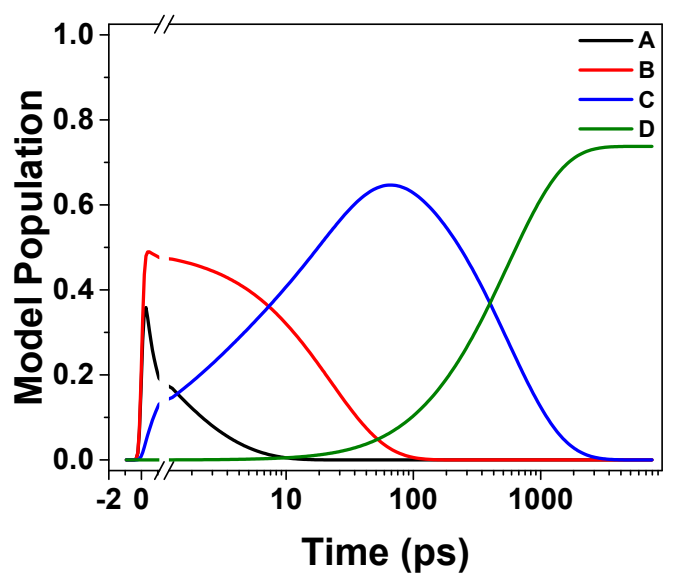

Figure S18. (A) FsTA spectra at selected time delays, (B) evolution-associated spectra, (C) single-wavelength kinetics at 568 (black), 593 (red), 625 (blue), 653 (green), 777 (orange), 924 (pink), 1055 (dark yellow), and $1340 \mathrm{~nm}$ (magenta), and (D) population dynamics obtained by global analysis with the kinetic model described in eq. 1 of the TDI-Ph-TDI chlorobenzene solvent-vapor annealed film, $\lambda_{\mathrm{ex}}=680 \mathrm{~nm}$. 
nsTA Data of the TDI-Ph-TDI Films

A
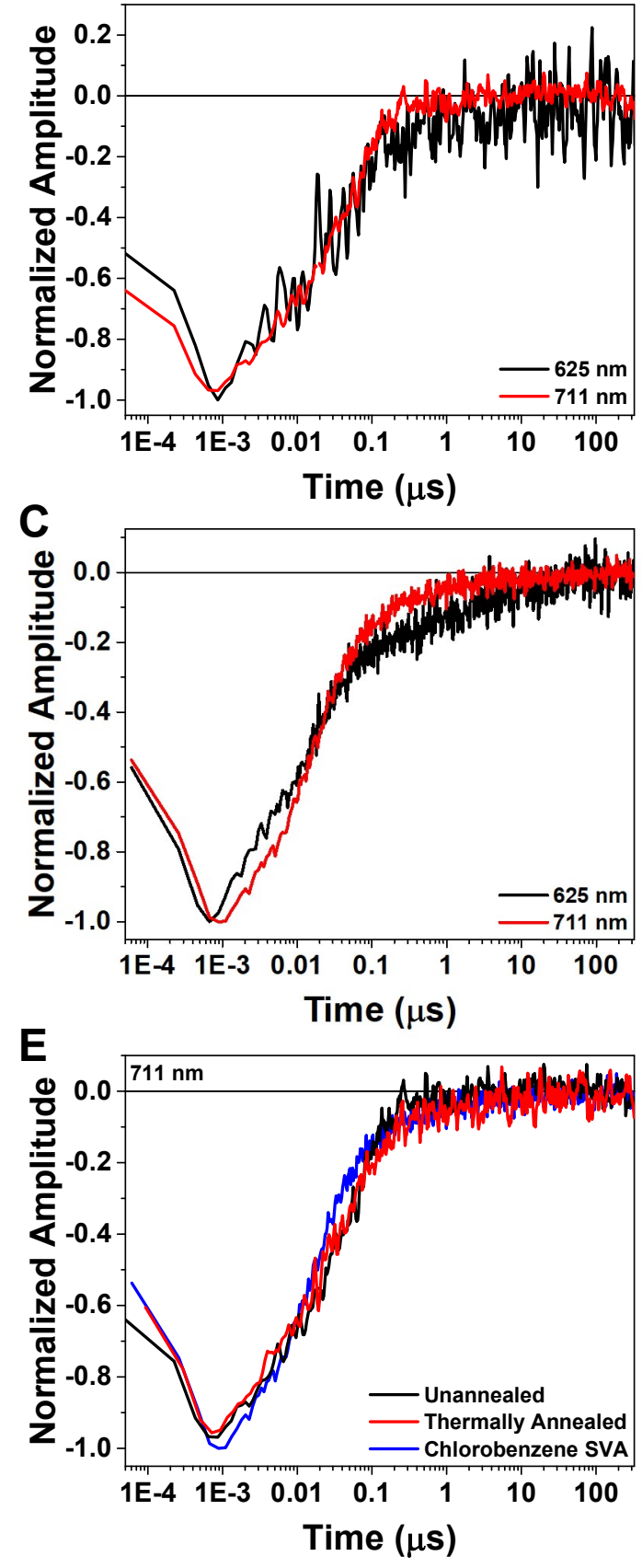

B

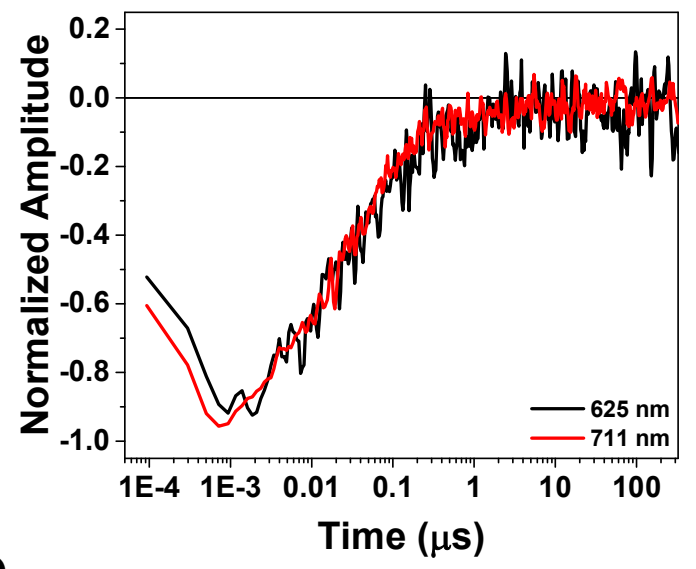

D

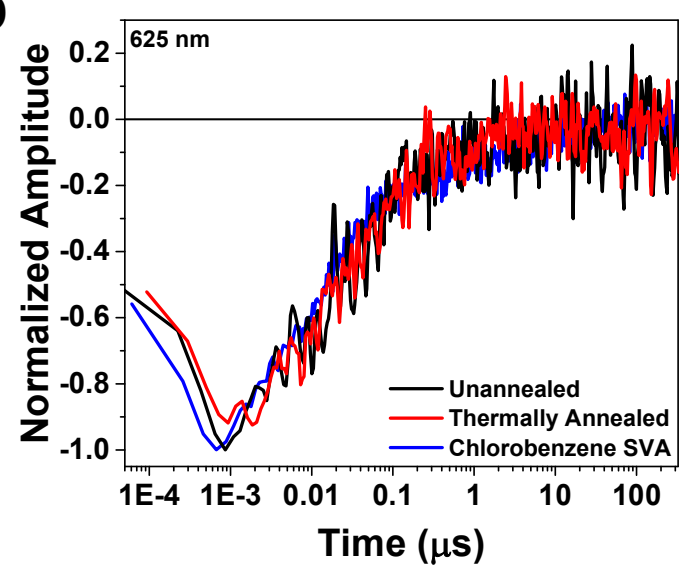

Figure S19. Comparisons of the single-wavelength kinetics at 625 (black) and $711 \mathrm{~nm}$ (red) of the TDI-Ph-TDI (A) unannealed, (B) thermally annealed, and (C) chlorobenzene SVA films. Comparison of the single-wavelength kinetics at (D) 625 and (E) $711 \mathrm{~nm}$ of the three films. The single-wavelength kinetics of the TDI-Ph-TDI unannealed and thermally annealed films were smoothed with 3-point adjacent averaging. 


\section{Full nsTA Spectra of the TDI-Ph-TDI Chlorobenzene SVA Film}

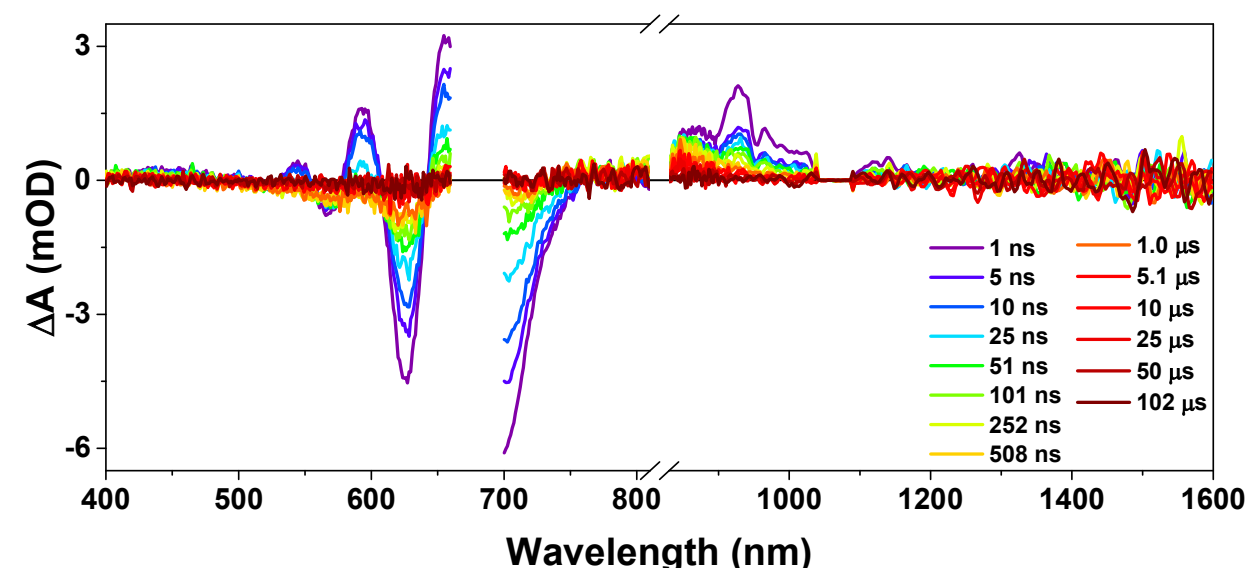

Figure S20. NsTA spectra at selected time delays of the TDI-Ph-TDI chlorobenzene solventvapor annealed film, $\lambda_{\mathrm{ex}}=680 \mathrm{~nm}$.

\section{Comparisons Between TDI-Ph-TDI in Solution and Film}

A

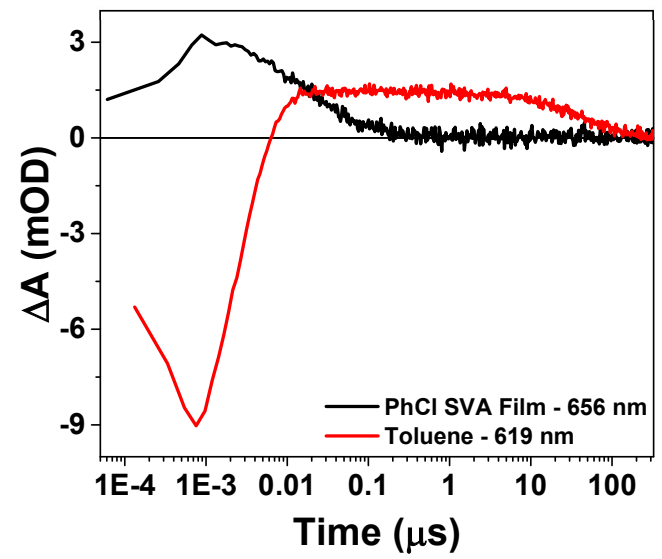

B

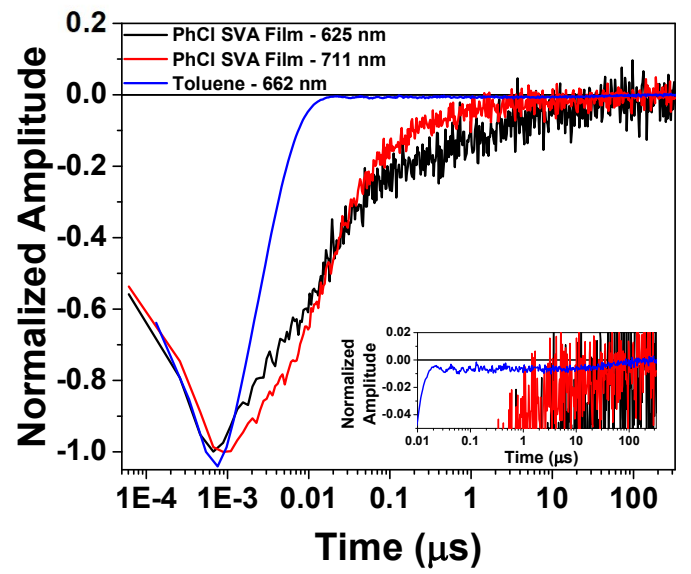

Figure S21. Comparison of the single-wavelength kinetics at the triplet excited-state absorption (ESA) and ground-state bleach (GSB) of TDI-Ph-TDI in toluene and the TDI-Ph-TDI chlorobenzene SVA film. 


\section{Thermal Difference Spectra of the TDI-Ph-TDI Films}

A

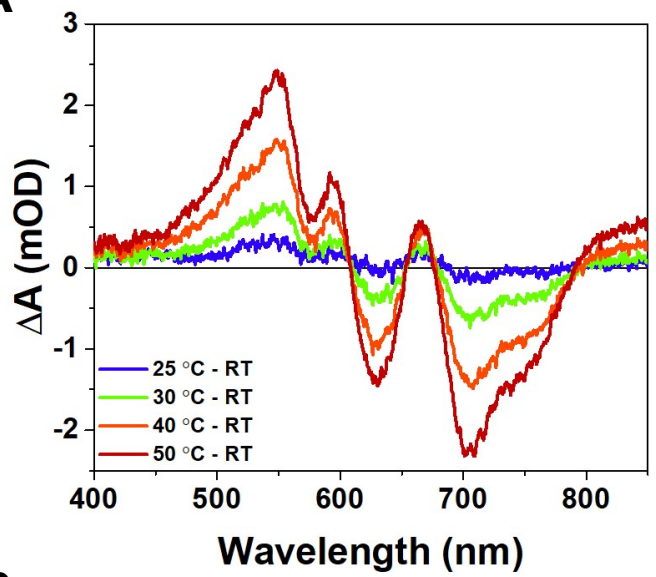

B

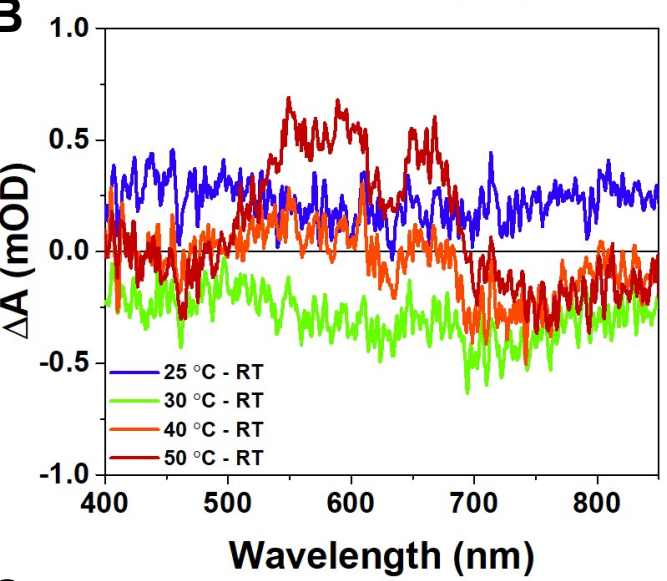

C

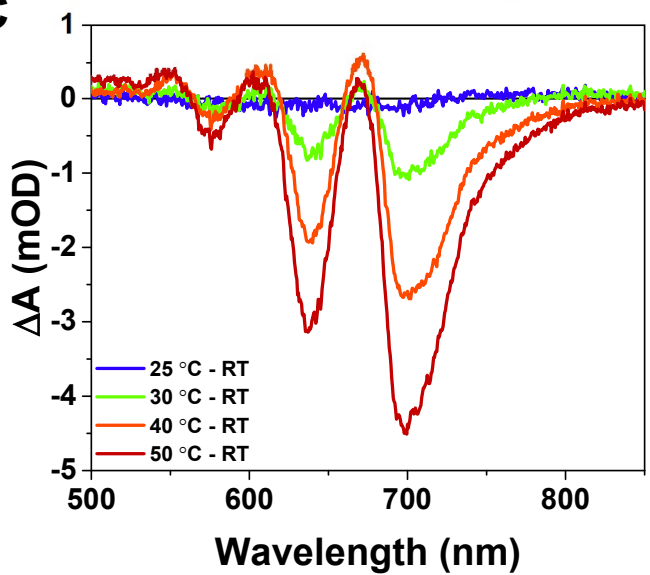

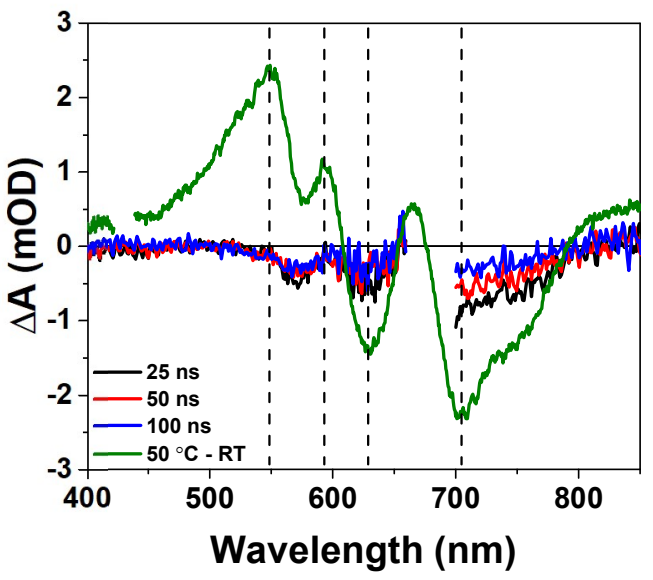
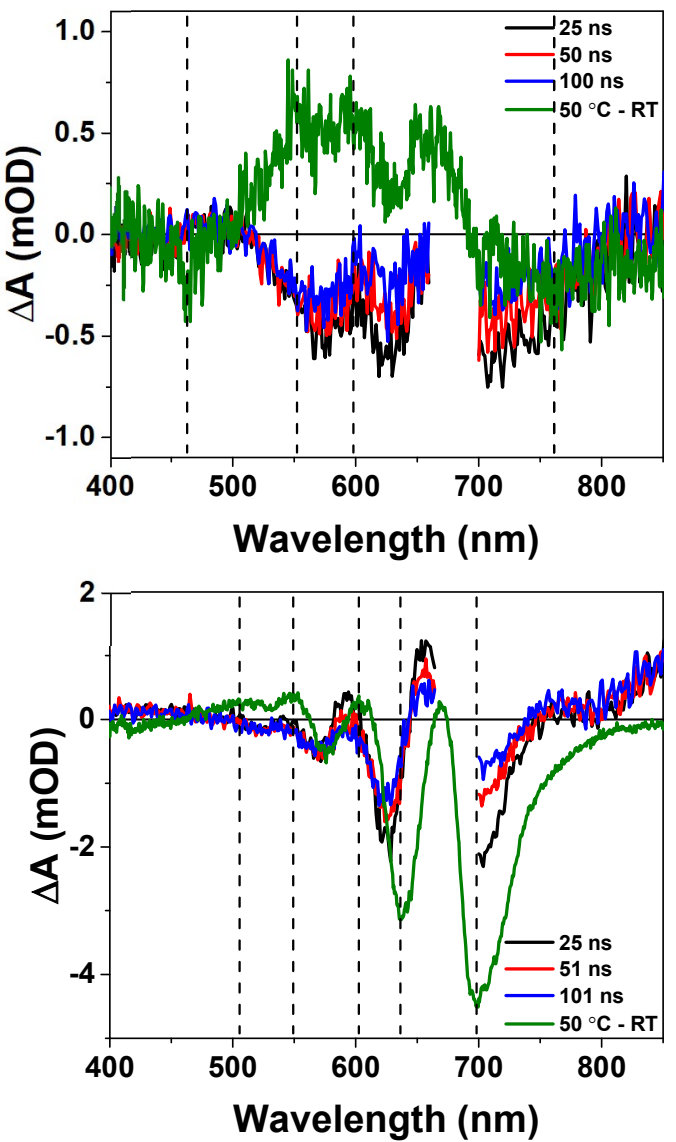

Figure S22. Thermal difference spectra and comparisons of the thermal difference spectra to nsTA time traces of the TDI-Ph-TDI (A) unannealed, (B) thermally annealed, and (C) chlorobenzene SVA films. The thermal difference spectra of the TDI-Ph-TDI thermally annealed film were smoothed with 5-point adjacent averaging. 


\section{Computational Data}

TDI-Ph-TDI: Full Structure (MMFF94 Force Field)

\begin{tabular}{|c|c|c|c|}
\hline $\mathrm{C}$ & -0.46179 & 0.89675 & -0.69425 \\
\hline $\mathrm{C}$ & -1.23397 & 1.95177 & -0.18342 \\
\hline $\mathrm{C}$ & -0.52555 & 3.05977 & 0.34453 \\
\hline $\mathrm{C}$ & 0.92731 & 3.06761 & 0.37397 \\
\hline $\mathrm{C}$ & 1.67014 & 1.99472 & -0.17901 \\
\hline $\mathrm{C}$ & 0.93211 & 0.92179 & -0.70140 \\
\hline $\mathrm{H}$ & -0.91936 & 0.01033 & -1.12386 \\
\hline $\mathrm{C}$ & -1.26706 & 4.16091 & 0.84087 \\
\hline $\mathrm{C}$ & 1.63501 & 4.14897 & 0.95520 \\
\hline $\mathrm{H}$ & 1.41826 & 0.04851 & -1.12666 \\
\hline $\mathrm{C}$ & 0.86436 & 5.21126 & 1.45222 \\
\hline $\mathrm{C}$ & -0.52829 & 5.22172 & 1.38760 \\
\hline $\mathrm{H}$ & 1.32333 & 6.08929 & 1.89754 \\
\hline $\mathrm{H}$ & -1.01308 & 6.10155 & 1.80071 \\
\hline $\mathrm{C}$ & -2.67061 & 1.92479 & -0.18850 \\
\hline $\mathrm{C}$ & -3.39847 & 3.04556 & 0.28308 \\
\hline $\mathrm{C}$ & -3.42542 & 0.81806 & -0.65195 \\
\hline $\mathrm{C}$ & -2.70264 & 4.17577 & 0.78021 \\
\hline $\mathrm{C}$ & -4.83476 & 3.03724 & 0.25432 \\
\hline $\mathrm{C}$ & -4.81838 & 0.80563 & -0.65525 \\
\hline $\mathrm{H}$ & -2.94354 & -0.08493 & -1.01703 \\
\hline $\mathrm{C}$ & -3.48706 & 5.28181 & 1.19470 \\
\hline $\mathrm{C}$ & -5.54991 & 4.15806 & 0.66903 \\
\hline $\mathrm{C}$ & -5.52231 & 1.91471 & -0.20214 \\
\hline $\mathrm{H}$ & -5.34400 & -0.07946 & -1.01091 \\
\hline $\mathrm{C}$ & -4.87860 & 5.28240 & 1.13282 \\
\hline $\mathrm{H}$ & -3.02928 & 6.19439 & 1.56702 \\
\hline $\mathrm{H}$ & -5.42960 & 6.16599 & 1.45181 \\
\hline $\mathrm{C}$ & 3.10655 & 2.02063 & -0.19992 \\
\hline $\mathrm{C}$ & 3.79929 & 3.09142 & 0.41653 \\
\hline $\mathrm{C}$ & 3.89547 & 1.01710 & -0.81742 \\
\hline $\mathrm{C}$ & 3.07003 & 4.14498 & 1.02147 \\
\hline $\mathrm{C}$ & 5.23516 & 3.10997 & 0.42651 \\
\hline $\mathrm{C}$ & 5.28806 & 1.06596 & -0.84551 \\
\hline $\mathrm{H}$ & 3.44049 & 0.16986 & -1.32349 \\
\hline $\mathrm{C}$ & 3.82214 & 5.15626 & 1.67090 \\
\hline $\mathrm{C}$ & 5.91836 & 4.11953 & 1.09690 \\
\hline $\mathrm{C}$ & 5.95669 & 2.11580 & -0.22786 \\
\hline $\mathrm{H}$ & 5.84079 & 0.28043 & -1.35830 \\
\hline $\mathrm{C}$ & 5.21427 & 5.14007 & 1.72415 \\
\hline $\mathrm{H}$ & 3.33733 & 5.98563 & 2.17888 \\
\hline $\mathrm{H}$ & 5.73990 & 5.93324 & 2.25338 \\
\hline $\mathrm{C}$ & -7.03052 & 4.18262 & 0.60881 \\
\hline $\mathrm{C}$ & -7.00531 & 1.86565 & -0.19060 \\
\hline $\mathrm{N}$ & -7.66471 & 2.96076 & 0.37405 \\
\hline $\mathrm{O}$ & -7.59574 & 5.26808 & 0.72342 \\
\hline $\mathrm{O}$ & -7.55521 & 0.87456 & -0.66744 \\
\hline $\mathrm{C}$ & 7.39761 & 4.11564 & 1.17357 \\
\hline $\mathrm{C}$ & 7.43575 & 2.17916 & -0.31648 \\
\hline $\mathrm{N}$ & 8.07422 & 3.23821 & 0.32989 \\
\hline $\mathrm{O}$ & 8.02324 & 1.30344 & -0.94774 \\
\hline
\end{tabular}

$\begin{array}{lccc}\mathrm{O} & 7.94007 & 4.87137 & 1.97512 \\ \mathrm{C} & 9.55484 & 3.28691 & 0.26144 \\ \mathrm{H} & 9.85105 & 2.74417 & -0.64541 \\ \mathrm{C} & -9.09541 & 2.96155 & 0.37015 \\ \mathrm{C} & -9.71946 & 2.96900 & -0.90491 \\ \mathrm{C} & -9.86983 & 3.02763 & 1.54491 \\ \mathrm{C} & -11.11228 & 3.08788 & -1.10776 \\ \mathrm{H} & -9.05472 & 2.90183 & -1.76229 \\ \mathrm{C} & -11.26133 & 3.16807 & 1.34250 \\ \mathrm{C} & -11.88367 & 3.17024 & 0.06863 \\ \mathrm{H} & -11.92109 & 3.25659 & 2.20218 \\ \mathrm{~N} & -13.31330 & 3.17828 & 0.06290 \\ \mathrm{C} & -13.94726 & 1.93844 & -0.02853 \\ \mathrm{C} & -13.96408 & 4.31588 & 0.54780 \\ \mathrm{C} & -15.42699 & 1.95680 & -0.08239 \\ \mathrm{O} & -13.38079 & 0.84719 & -0.03279 \\ \mathrm{C} & -15.44807 & 4.27243 & 0.57159 \\ \mathrm{O} & -13.40628 & 5.33589 & 0.94764 \\ \mathrm{C} & -16.13920 & 3.11291 & 0.22584 \\ \mathrm{C} & -16.09962 & 0.79248 & -0.43081 \\ \mathrm{C} & -16.14930 & 5.41963 & 0.92205 \\ \mathrm{C} & -17.57517 & 3.10295 & 0.20306 \\ \mathrm{C} & -17.49081 & 0.78864 & -0.48938 \\ \mathrm{H} & -15.54979 & -0.11834 & -0.66347 \\ \mathrm{C} & -17.54290 & 5.40798 & 0.92561 \\ \mathrm{H} & -15.62119 & 6.33349 & 1.19053 \\ \mathrm{C} & -18.30072 & 4.26342 & 0.57011 \\ \mathrm{C} & -18.27255 & 1.93140 & -0.18443 \\ \mathrm{H} & -17.95031 & -0.15548 & -0.76943 \\ \mathrm{H} & -18.02364 & 6.34175 & 1.20497 \\ \mathrm{C} & -19.73773 & 4.23690 & 0.56969 \\ \mathrm{C} & -19.70714 & 1.94406 & -0.25180 \\ \mathrm{C} & -20.44696 & 3.08789 & 0.13909 \\ \mathrm{C} & -20.50969 & 5.33244 & 0.98771 \\ \mathrm{C} & -20.44607 & 0.83998 & -0.70478 \\ \mathrm{C} & -21.89910 & 3.08234 & 0.09887 \\ \mathrm{C} & -26.20328 & 3.06555 & -0.02844 \\ \mathrm{C} & -21.90403 & 5.31012 & 0.99232 \\ \mathrm{C} & -20.05107 & 6.25099 & 1.34232 \\ \mathrm{C} & -21.83737 & 0.85195 & -0.78750 \\ \mathrm{H} & -19.96219 & -0.07615 & -1.03078 \\ \mathrm{C} & -22.64210 & 4.19949 & 0.55527 \\ \mathrm{C} & -22.60590 & 1.95980 & -0.39958 \\ \mathrm{H} & -22.39107 & 6.21707 & 1.33907 \\ \mathrm{H} & -22.29749 & -0.06050 & -1.15590 \\ \mathrm{C} & -24.07879 & 4.17985 & 0.56361 \\ & -24.03835 & 1.97066 & -0.49716 \\ \mathrm{C} & -24.87107 & 5.071867 & 0.01353 \\ & & & 1.10913\end{array}$




\begin{tabular}{|c|c|c|c|}
\hline I & -24.41788 & 6.10283 & 1.55606 \\
\hline c & -26.17570 & 0.95477 & -1.19005 \\
\hline $\mathrm{H}$ & -24.29870 & 0.05596 & -1.52931 \\
\hline c & -26.88121 & 2.02552 & -0.65534 \\
\hline & -26.92966 & 4.10323 & 0.54730 \\
\hline $\mathrm{H}$ & -26.82100 & 6.00617 & 1.56054 \\
\hline & -26.69814 & 0.13700 & -1.68369 \\
\hline & -28.35474 & 2.05922 & -0.79771 \\
\hline & -28.41069 & 4.05120 & 0.61210 \\
\hline $\mathrm{N}$ & -29.04611 & 2.97355 & -0.00801 \\
\hline $\mathrm{O}$ & -28.87520 & 1.29838 & -1.60886 \\
\hline $\mathrm{O}$ & -29.00261 & 4.95359 & 1.19991 \\
\hline $\mathrm{C}$ & -30.52939 & 2.96881 & -0.00442 \\
\hline & -30.839 & 3.48 & 0.91463 \\
\hline & -11.66493 & 3.16839 & -2.55558 \\
\hline ( & -9.34509 & 2.90903 & 3.00025 \\
\hline $\mathrm{C}$ & -10.37103 & 2.19224 & 3.92765 \\
\hline I & -11.26710 & 2.79544 & 4.10864 \\
\hline $\mathrm{H}$ & -10.68261 & 1.22938 & 3.50638 \\
\hline $\mathrm{H}$ & -9.9 & 1.9 & \\
\hline C & -8.0 & 2.08 & \\
\hline $\mathrm{H}$ & -8.11971 & 1.12435 & 2.62327 \\
\hline $\mathrm{H}$ & -7.16321 & 2.61428 & 2.79439 \\
\hline $\mathrm{H}$ & -7.83653 & 1.85869 & 4.20412 \\
\hline C & -9.11272 & 4.31707 & 3.58113 \\
\hline $\mathrm{H}$ & -8.31019 & 4.84680 & \\
\hline $\mathrm{H}$ & -10. & & \\
\hline $\mathrm{H}$ & -8.8 & 4.2 & \\
\hline $\mathrm{C}$ & -12.2 & 1.80037 & -2.9 \\
\hline $\mathrm{H}$ & -11.49921 & 0.99683 & -2.81392 \\
\hline $\mathrm{H}$ & -13.14540 & 1.54131 & -2.47374 \\
\hline $\mathrm{H}$ & -12.46366 & 1.79678 & -4.06411 \\
\hline $\mathrm{C}$ & -12.76329 & 4.24550 & -2.71484 \\
\hline $\mathrm{H}$ & -13.71312 & 3.95132 & -2.26326 \\
\hline $\mathrm{H}$ & -12.4 & 35 & -2.27430 \\
\hline $\mathrm{H}$ & -12.9 & 4.42932 & -3.77208 \\
\hline $\mathrm{C}$ & -10.57643 & 3.54966 & -3.60070 \\
\hline $\mathrm{H}$ & -10.06686 & 4.48122 & -3.32834 \\
\hline $\mathrm{H}$ & -9.82396 & 2.76112 & -3.71714 \\
\hline $\mathrm{H}$ & -11.01317 & 3.69591 & -4.59651 \\
\hline $\mathrm{C}$ & 10.10112 & 4.72613 & 0.07202 \\
\hline $\mathrm{H}$ & & 5.28749 & -0.59720 \\
\hline $\mathrm{H}$ & 10.11558 & 5.25641 & 1.03088 \\
\hline C & 10.2 & 2.58 & 1.47 \\
\hline $\mathrm{H}$ & 11.22967 & 2.96546 & 1.61607 \\
\hline $\mathrm{H}$ & 9.67274 & 2.81591 & 2.40316 \\
\hline C & 10.29512 & 1.06316 & 1.30135 \\
\hline $\mathrm{H}$ & 9.30482 & 0.61445 & 1.43811 \\
\hline $\mathrm{H}$ & 10.62132 & 0.83128 & 0.28026 \\
\hline $\mathrm{C}$ & 11.28819 & & 2.28379 \\
\hline $\mathrm{H}$ & & & \\
\hline $\mathrm{H}$ & 12.24941 & 0.95965 & 2.21216 \\
\hline $\mathrm{C}$ & 11.50492 & -1.04882 & 1.98145 \\
\hline $\mathrm{H}$ & 10.57479 & -1.60166 & 2.15917 \\
\hline $\mathrm{H}$ & 11.75677 & -1.17324 & 0.92094 \\
\hline $\mathrm{C}$ & 12.63185 & -1.63419 & 2.83461 \\
\hline
\end{tabular}

\begin{tabular}{|c|c|c|c|}
\hline $\mathrm{I}$ & 13.54767 & -1.04997 & 2.68129 \\
\hline $\mathrm{H}$ & 12.37157 & -1.55401 & 3.89682 \\
\hline & 12.89874 & -3.09603 & 2.47562 \\
\hline $\mathrm{H}$ & 12.00206 & -3.69622 & 2.66802 \\
\hline $\mathrm{H}$ & 13.12363 & -3.18235 & 1.40599 \\
\hline $\mathrm{C}$ & 14.06365 & -3.66228 & 3.27190 \\
\hline $\mathrm{H}$ & 13.86342 & -3.61814 & 4.34698 \\
\hline & 14.23581 & -4.70837 & .99978 \\
\hline & 14.98390 & -3.10441 & 3.07012 \\
\hline $\mathrm{C}$ & 11.51664 & 4.74535 & -0.52371 \\
\hline $\mathrm{H}$ & 12.18762 & 4.11206 & 0.06579 \\
\hline $\mathrm{H}$ & 11.49349 & & -1.53731 \\
\hline $\mathrm{C}$ & 12.08680 & & \\
\hline $\mathrm{H}$ & 12.03643 & & 0.43482 \\
\hline $\mathrm{H}$ & 11.47675 & 6.78911 & -1.23010 \\
\hline C & 13.54013 & 6.16135 & -1.04493 \\
\hline I & 14.13616 & 5.50666 & -0.39712 \\
\hline $\mathrm{H}$ & 13.59364 & 5.74733 & -2.05906 \\
\hline $\mathrm{C}$ & 14.13790 & 7.56891 & -1.02971 \\
\hline $\mathrm{H}$ & 14.05260 & & -0.02198 \\
\hline $\mathrm{H}$ & 13.5 & & 387 \\
\hline $\mathrm{C}$ & 15.60707 & 55145 & -1.45169 \\
\hline H & 16.17907 & 6.89960 & -0.78090 \\
\hline $\mathrm{H}$ & 15.69986 & 7.13796 & -2.46259 \\
\hline C & 16.21216 & 8.94580 & -1.42357 \\
\hline $\mathrm{H}$ & 16.16192 & 9.37499 & -0.41771 \\
\hline $\mathrm{H}$ & 17.26 & 8.90852 & -1.72426 \\
\hline $\mathrm{H}$ & 15.68 & & \\
\hline $\mathrm{C}$ & -31 . & & \\
\hline $\mathrm{H}$ & -31.1 & 5020 & -0.87187 \\
\hline $\mathrm{H}$ & -30.55494 & 93921 & 0.79798 \\
\hline $\mathrm{C}$ & -31.10578 & 3.74157 & -1.22100 \\
\hline $\mathrm{H}$ & -32.06677 & 3.30785 & -1.51662 \\
\hline $\mathrm{H}$ & -30.45 & 3.64082 & -2.09568 \\
\hline $\mathrm{C}$ & -32.60198 & 1.57546 & 0.59353 \\
\hline $\mathrm{H}$ & -33.18700 & 29843 & 0.01567 \\
\hline $\mathrm{H}$ & -32.6 & 90851 & 1.63799 \\
\hline $\mathrm{C}$ & -33.25850 & 0.19815 & 0.47099 \\
\hline $\mathrm{H}$ & -33.12092 & 0.18348 & -0.54819 \\
\hline $\mathrm{H}$ & -32.76748 & -0.50829 & 1.15066 \\
\hline $\mathrm{C}$ & -34.75545 & 0.26889 & 0.78058 \\
\hline $\mathrm{H}$ & -35.22811 & 1.01122 & 0.12545 \\
\hline $\mathrm{H}$ & -34.90441 & & 1.81275 \\
\hline $\mathrm{C}$ & & & 0.57764 \\
\hline $\mathrm{H}$ & & & 1.26812 \\
\hline $\mathrm{H}$ & -35.23858 & -1.44696 & -0.44021 \\
\hline $\mathrm{C}$ & -36.94241 & -0.99224 & 0.80158 \\
\hline $\mathrm{H}$ & -37.37456 & -0.25532 & 0.11431 \\
\hline $\mathrm{H}$ & -37.14747 & -0.64461 & 1.82064 \\
\hline $\mathrm{C}$ & -37.62429 & -2.33326 & 0.58233 \\
\hline $\mathrm{H}$ & -38.70332 & -2.24003 & 0.74032 \\
\hline $\mathrm{H}$ & -37.46104 & -2.69420 & -0.43828 \\
\hline $\mathrm{H}$ & & -3.08621 & 1.27878 \\
\hline C & -31.32127 & 5.23117 & -0.91685 \\
\hline $\mathrm{H}$ & -31.65930 & 5.35150 & 0.11937 \\
\hline $\mathrm{H}$ & -30.37343 & 5.77243 & -1.01477 \\
\hline
\end{tabular}




$\begin{array}{llllllll}\mathrm{C} & -32.37444 & 5.85572 & -1.83644 & \mathrm{H} & -33.72938 & 7.84345 & -3.23159 \\ \mathrm{H} & -33.29337 & 5.25833 & -1.78892 & \mathrm{C} & -34.26341 & 9.25008 & -1.67799 \\ \mathrm{H} & -32.02745 & 5.83495 & -2.87607 & \mathrm{H} & -33.43855 & 9.93343 & -1.91029 \\ \mathrm{C} & -32.68925 & 7.29390 & -1.41625 & \mathrm{H} & -34.39417 & 9.25790 & -0.58941 \\ \mathrm{H} & -31.81976 & 7.93301 & -1.61102 & \mathrm{C} & -35.53868 & 9.75940 & -2.33050 \\ \mathrm{H} & -32.87817 & 7.32780 & -0.33607 & \mathrm{H} & -35.76378 & 10.77245 & -1.98254 \\ \mathrm{C} & -33.91549 & 7.83841 & -2.15103 & \mathrm{H} & -35.43958 & 9.78684 & -3.42005 \\ \mathrm{H} & -34.77102 & 7.17505 & -1.97318 & \mathrm{H} & -36.38993 & 9.11859 & -2.07830\end{array}$

TDI-Ph-TDI: Simplified Singlet Ground State (B3LYP/6-31G*)

\begin{tabular}{|c|c|c|c|}
\hline & 9.9892904761 & -2.3989560027 & \\
\hline & 9.2496235501 & -1.2172686663 & 0.1980595780 \\
\hline & 9.9589349717 & 0.0216518773 & 0.0943288830 \\
\hline & 11.3954312742 & 0.0220119049 & 0.0167896745 \\
\hline & 2.1112758165 & -1.2177601771 & 0.0245864294 \\
\hline & 11.3773244077 & -2.3992490504 & 0.1184686560 \\
\hline & 9.4900690135 & -3.3578411962 & 0.2773420420 \\
\hline & 9.2421952300 & 1.2604854869 & 0.0656223549 \\
\hline & 12.1052138920 & 1.2620717388 & -0.0688981293 \\
\hline & 11.8806900814 & -3.3585502896 & \\
\hline & 11.3656518641 & 2.4438520347 & 019 \\
\hline & 9.9764988873 & 2.443 & -0.0 \\
\hline & 11.8651103522 & 082524 & -0.13 \\
\hline & 9.4724007222 & 3.4019 & -0.016 \\
\hline & 7.7852079467 & -1.221 & 0.289 \\
\hline & 7.0805 & & \\
\hline $\mathrm{C}$ & 7.0441886132 & 11887 & \\
\hline $\mathrm{C}$ & 7.77582 & & \\
\hline $\mathrm{C}$ & & & \\
\hline $\mathrm{C}$ & 5.64 & -2.3 & \\
\hline & 7.54 & -3.3 & 0.4 \\
\hline 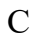 & 7.025 & 2.441 & 0.02 \\
\hline $\mathrm{C}$ & & & \\
\hline $\mathrm{C}$ & 4.9461346032 & -1.1994731524 & 0.418 \\
\hline $\mathrm{H}$ & & -3.3174830943 & \\
\hline $\mathrm{C}$ & & & \\
\hline & & & -0.0 \\
\hline & 5.06 & 3.3. & -0.0 \\
\hline $\mathrm{C}$ & 13.57 & 9117603 & -0.06992 \\
\hline $\mathrm{C}$ & 14.27195 & 2628 & -0.1568997198 \\
\hline $\mathrm{C}$ & 14.3232 & 20291 & 0569915 \\
\hline $\mathrm{C}$ & 13.5698203260 & 1.2675819007 & 4981856 \\
\hline $\mathrm{C}$ & 15.6982428380 & 0.0227328066 & -0.2506750745 \\
\hline $\mathrm{C}$ & & -2.3970774482 & \\
\hline & 13.82 & -3.36 & -0.01 \\
\hline $\mathrm{C}$ & 14.31 & 1478580 & -0.23 \\
\hline $\mathrm{C}$ & 16.406 & 1.2457211325 & -0.33 \\
\hline $\mathrm{C}$ & 16.4102105509 & -1.2004936814 & -0.2590740059 \\
\hline $\mathrm{H}$ & 16.2795958141 & -3.3251313746 & -0.1806861737 \\
\hline $\mathrm{C}$ & 15.7070639385 & 2.4420806513 & -0.3226419670 \\
\hline $\mathrm{H}$ & 13.8141840084 & 3.4118226558 & -0.2254516502 \\
\hline $\mathrm{H}$ & 16.2645059456 & 3.3706739673 & -0.3864495109 \\
\hline $\mathrm{C}$ & 3.4556832370 & 1.2579788012 & 0.2156435516 \\
\hline & 3.4653047392 & -1.2261871163 & 0.4685694820 \\
\hline
\end{tabular}

\begin{abstract}
2.8082038693
0.0182483086

2.2882397427

0.4062730847

2.8127729286

2.8321926678

$-2.2675473931$

0.0865998187

$\begin{array}{llll}17.8868053465 & -1.2169770063 & -0.3593341751\end{array}$

$\begin{array}{llll}18.5317585960 & 0.0243636061 & -0.4397674435\end{array}$

$\begin{array}{llll}18.5400376605 & -2.2528539100 & -0.3727020548\end{array}$

$\begin{array}{llll}18.5159212650 & 2.3164171590 & -0.5144409043\end{array}$

$\begin{array}{llll}19.9952431197 & -0.0068054373 & -0.5355543174\end{array}$

$\begin{array}{lll}20.4095018236 & -0.5335156572 & 0.3273042337\end{array}$

$\begin{array}{llll}20.2967822665 & -0.5406717289 & -1.4402649453\end{array}$

$\begin{array}{llll}20.3458794340 & 1.0221863077 & -0.5638443551\end{array}$

$\begin{array}{llll}1.3558315768 & 0.0107537137 & 0.3101174957\end{array}$

$\begin{array}{llll}0.8712354361 & -0.1099189473 & -0.9916277769\end{array}$

$\begin{array}{lll}0.4884560638 & 0.1245613381 & 1.4111479422\end{array}$

$\begin{array}{lll}-0.4855401034 & -0.1359868688 & -1.3360320195\end{array}$

$\begin{array}{lll}1.6185165899 & -0.1890136798 & -1.7698411204\end{array}$

$\begin{array}{lll}-0.8684310177 & 0.0989015675 & 1.0667388890\end{array}$

$\begin{array}{lll}-1.3529653576 & -0.0212581674 & -0.2350254380\end{array}$

$\begin{array}{lll}-1.6157308015 & 0.1783195232 & 1.8449034901\end{array}$

$\begin{array}{lll}-2.8051388691 & -0.0265308031 & -0.3328602765\end{array}$

$\begin{array}{llll}-3.4557014071 & -1.2641670963 & -0.1393647099\end{array}$

$\begin{array}{llll}-3.4596561921 & 1.2189330603 & -0.4021273944\end{array}$

$\begin{array}{lll}-4.9365322166 & -1.2413423225 & -0.1322323380\end{array}$

$\begin{array}{llll}-2.8152521931 & -2.2947558597 & -0.0010841714\end{array}$

$\begin{array}{llll}-4.9408308301 & 1.1947412949 & -0.3625861424\end{array}$

$\begin{array}{llll}-2.8241701673 & 2.2590554048 & -0.4967175980\end{array}$

$\begin{array}{llll}-5.6496885003 & -0.0229496444 & -0.2308277622\end{array}$

$\begin{array}{llll}-5.6316574274 & -2.4331669424 & -0.0045147064\end{array}$

$\begin{array}{llll}-5.6405522652 & 2.3880343876 & -0.4448332018\end{array}$

$\begin{array}{lll}-7.0786141822 & -0.0219192222 & -0.1903801697\end{array}$

$\begin{array}{lll}-7.0286381572 & -2.4418342240 & 0.0187659977\end{array}$

$\begin{array}{llll}-5.0683315549 & -3.3566356764 & 0.0793124956\end{array}$

$\begin{array}{lll}-7.0369305520 & 2.3984108929 & -0.3923829739\end{array}$

$\begin{array}{llll}-5.0815557558 & 3.3123351967 & -0.5470785358\end{array}$

$\begin{array}{llll}-7.7808399390 & 1.2211318747 & -0.2610160169\end{array}$

$\begin{array}{llll}-7.7768523825 & -1.2634537902 & -0.0738285619\end{array}$

$\begin{array}{lll}-7.5253179540 & -3.3992745349 & 0.1205897859\end{array}$

$\begin{array}{llll}-7.5364904684 & 3.3574342328 & -0.4587386628\end{array}$

$\begin{array}{llll}-9.2460963169 & 1.2191045895 & -0.1850301435\end{array}$

$\begin{array}{llll}-9.2436557146 & -1.2585205883 & -0.0500703815\end{array}$

$\begin{array}{llll}-9.9583451861 & -0.0188038231 & -0.0893695310\end{array}$

$\begin{array}{llll}-9.9838592893 & 2.4018872961 & -0.2011942780\end{array}$

$\begin{array}{llll}-9.9804377188 & -2.4401041248 & 0.0149891590\end{array}$
\end{abstract}




$\begin{array}{lrrrl}\mathrm{C} & -11.3957012667 & -0.0171838610 & -0.0307911366 & \mathrm{H} \\ \mathrm{C} & -11.3728947140 & 2.4041260849 & -0.1310706838 & \mathrm{H} \\ \mathrm{H} & -9.4823638408 & 3.3601006695 & -0.2648755695 & \mathrm{H} \\ \mathrm{C} & -11.3703689613 & -2.4390436683 & 0.0598855119 & \mathrm{C} \\ \mathrm{H} & -9.4777386864 & -3.3996268152 & 0.0306096152 & \mathrm{C} \\ \mathrm{C} & -12.1096779018 & 1.2235810429 & -0.0477292085 & \mathrm{C} \\ \mathrm{C} & -12.1082796923 & -1.2563077521 & 0.0452008461 & \mathrm{H} \\ \mathrm{H} & -11.8747502598 & 3.3641688968 & -0.1442954934 & \mathrm{H} \\ \mathrm{H} & -11.8718296265 & -3.3979450508 & 0.1121947362 & \mathrm{H} \\ \mathrm{C} & -13.5750345625 & 1.2307018066 & 0.0263823159 & \mathrm{C} \\ \mathrm{C} & -13.5739435963 & -1.259865869 & 0.1072379413 & \mathrm{H} \\ \mathrm{C} & -14.2744488438 & -0.0137987212 & 0.1019083401 & \mathrm{H} \\ \mathrm{C} & -14.3211958307 & 2.4141593721 & 0.0264492099 & \mathrm{H} \\ \mathrm{C} & -14.3196449172 & -2.4414978406 & 0.1749620094 & \mathrm{C} \\ \mathrm{C} & -15.7019598879 & -0.0121920595 & 0.1741238569 & \mathrm{H} \\ \mathrm{C} & -15.7166734076 & 2.4077470147 & 0.0997050990 & \mathrm{H} \\ \mathrm{H} & -13.8240446231 & 3.3750241477 & -0.0302313159 & \mathrm{H} \\ \mathrm{C} & -15.7150768056 & -2.4316134798 & 0.2441065211 & \mathrm{C} \\ \mathrm{H} & -13.8222164085 & -3.4038481658 & 0.1761332543 & \mathrm{H} \\ \mathrm{C} & -16.4126463441 & -1.2343404000 & 0.2461903300 & \mathrm{H} \\ \mathrm{C} & -16.4123395060 & 1.2120265753 & 0.1732164568 & \mathrm{H} \\ \mathrm{H} & -16.2774060729 & 3.3366713507 & 0.0997719579 & \mathrm{C} \\ \mathrm{H} & -16.2746132732 & -3.3595354979 & 0.2985856720 & \mathrm{H} \\ \mathrm{C} & -17.8918559635 & -1.2571852342 & 0.3246609164 & \mathrm{H} \\ \mathrm{C} & -17.8902788022 & 1.2303982183 & 0.2504948271 & \mathrm{H} \\ \mathrm{N} & -18.5379528531 & -0.0101478089 & 0.3208560096 & \mathrm{C} \\ \mathrm{O} & -18.5265552423 & -2.3024042789 & 0.3898958885 & \mathrm{H} \\ \mathrm{O} & -18.5424061063 & 2.2670478397 & 0.2539039379 & \mathrm{H} \\ \mathrm{C} & -20.0026756054 & 0.0229225484 & 0.3945014449 & \mathrm{H}\end{array}$

$\begin{array}{rrr}-20.3163801046 & 0.5708128391 & 1.2864114619 \\ -20.4048101989 & 0.5363569326 & -0.4821763438 \\ -20.3542300940 & -1.0054350762 & 0.4326276878 \\ -0.8912211807 & -0.2186375612 & -2.8278761014 \\ 0.8943164234 & 0.2053156822 & 2.9029548366 \\ -0.2565463064 & 0.7784326153 & 3.7642099340 \\ -0.5868137008 & 1.7594294718 & 3.4038097093 \\ -1.1251594205 & 0.1131513292 & 3.8015653627 \\ 0.0937292802 & 0.8988666855 & 4.7949860637 \\ 1.2020737964 & -1.2236565962 & 3.4133009690 \\ 0.3154452311 & -1.8623495034 & 3.3326210940 \\ 2.0000368467 & -1.6991872688 & 2.8381959927 \\ 1.5031746531 & -1.1881844648 & 4.4680539198 \\ 2.1201412899 & 1.1172535284 & 3.1481513876 \\ 3.0509704083 & 0.6651523587 & 2.8002194994 \\ 2.0040641551 & 2.0874652910 & 2.6560817198 \\ 2.2320036252 & 1.2886671523 & 4.2251108281 \\ -2.1183220125 & -1.1294389307 & -3.0713352635 \\ -2.0043242251 & -2.0983271351 & -2.5761717317 \\ -3.0487352166 & -0.6747382700 & -2.7256120906 \\ -2.2297693775 & -1.3041027037 & -4.1478166524 \\ -1.1965084212 & 1.2095608110 & -3.3416834808 \\ -1.9946883173 & 1.6875622514 & -2.7690481929 \\ -0.3092140544 & 1.8473258244 & -3.2610668346 \\ -1.4960617586 & 1.1721073049 & -4.3968062047 \\ 0.2590614418 & -0.7951814220 & -3.6877230578 \\ 1.1285912305 & -0.1311511743 & -3.7263258695 \\ 0.5879769829 & -1.7758385406 & -3.3251912737 \\ -0.0911430027 & -0.9173104496 & -4.7183171925\end{array}$




\section{References}

1. Pisula, W.; Kastler, M.; Wasserfallen, D.; Robertson, J. W. F.; Nolde, F.; Kohl, C.; Müllen, K., Pronounced Supramolecular Order in Discotic Donor-Acceptor Mixtures. Angew. Chem., Int. Ed. 2006, 45, 819-823. 